NASA/TM-2012-217701

\title{
Scaling of Lift Degradation Due to Anti-Icing Fluids Based Upon the Aerodynamic Acceptance Test
}

Andy P. Broeren

Glenn Research Center, Cleveland, Ohio

James T. Riley

Federal Aviation Administration, William J. Hughes Technical Center, Atlantic City Airport, New Jersey 


\section{NASA STI Program ... in Profile}

Since its founding, NASA has been dedicated to the advancement of aeronautics and space science. The NASA Scientific and Technical Information (STI) program plays a key part in helping NASA maintain this important role.

The NASA STI Program operates under the auspices of the Agency Chief Information Officer. It collects, organizes, provides for archiving, and disseminates NASA's STI. The NASA STI program provides access to the NASA Aeronautics and Space Database and its public interface, the NASA Technical Reports Server, thus providing one of the largest collections of aeronautical and space science STI in the world. Results are published in both non-NASA channels and by NASA in the NASA STI Report Series, which includes the following report types:

- TECHNICAL PUBLICATION. Reports of completed research or a major significant phase of research that present the results of NASA programs and include extensive data or theoretical analysis. Includes compilations of significant scientific and technical data and information deemed to be of continuing reference value. NASA counterpart of peer-reviewed formal professional papers but has less stringent limitations on manuscript length and extent of graphic presentations.

- TECHNICAL MEMORANDUM. Scientific and technical findings that are preliminary or of specialized interest, e.g., quick release reports, working papers, and bibliographies that contain minimal annotation. Does not contain extensive analysis.

- CONTRACTOR REPORT. Scientific and technical findings by NASA-sponsored contractors and grantees.
- CONFERENCE PUBLICATION. Collected papers from scientific and technical conferences, symposia, seminars, or other meetings sponsored or cosponsored by NASA.

- SPECIAL PUBLICATION. Scientific, technical, or historical information from NASA programs, projects, and missions, often concerned with subjects having substantial public interest.

- TECHNICAL TRANSLATION. Englishlanguage translations of foreign scientific and technical material pertinent to NASA's mission.

Specialized services also include creating custom thesauri, building customized databases, organizing and publishing research results.

For more information about the NASA STI program, see the following:

- Access the NASA STI program home page at http://www.sti.nasa.gov

- E-mail your question to help@sti.nasa.gov

- Fax your question to the NASA STI Information Desk at 443-757-5803

- Phone the NASA STI Information Desk at 443-757-5802

- Write to:

STI Information Desk

NASA Center for AeroSpace Information

7115 Standard Drive

Hanover, MD 21076-1320 
NASA/TM-2012-217701

Scaling of Lift Degradation Due to Anti-Icing Fluids Based Upon the Aerodynamic Acceptance Test

Andy P. Broeren

Glenn Research Center, Cleveland, Ohio

James T. Riley

Federal Aviation Administration, William J. Hughes Technical Center, Atlantic City Airport, New Jersey

Prepared for the

Atmospheric Space Environments Conference

sponsored by the American Institute of Aeronautics and Astronautics

New Orleans, Louisiana, June 25-28, 2012

National Aeronautics and

Space Administration

Glenn Research Center

Cleveland, Ohio 44135 


\section{Acknowledgments}

The authors wish to acknowledge the contributions to this report from other members of the research team. Warren Underwood of the FAA and John D'Avirro, Michele Pineau and Marco Ruggi of APS Aviation provided invaluable insights into the history and characteristics of anti-icing fluids testing and results. The authors also appreciate the contributions of Catherine Clark and Marc MacMaster at NRC Canada in understanding and interpreting the wind-tunnel experimental methods and aerodynamic data. The support of these individuals is gratefully acknowledged. The NASA Aviation Safety Program, Atmospheric Environment Safety Technologies Project and the FAA Ground Icing Program also supported this work.

Trade names and trademarks are used in this report for identification only. Their usage does not constitute an official endorsement, either expressed or implied, by the National Aeronautics and Space Administration.

Level of Review: This material has been technically reviewed by technical management.

Available from

NASA Center for Aerospace Information 7115 Standard Drive

Hanover, MD 21076-1320
National Technical Information Service 5301 Shawnee Road Alexandria, VA 22312

Available electronically at http://www.sti.nasa.gov 


\title{
Scaling of Lift Degradation Due to Anti-Icing Fluids Based Upon the Aerodynamic Acceptance Test
}

\author{
Andy P. Broeren \\ National Aeronautics and Space Administration \\ Glenn Research Center \\ Cleveland, Ohio 44135 \\ James T. Riley \\ FAA William J. Hughes Technical Center \\ Atlantic City Airport, New Jersey 08405
}

\begin{abstract}
In recent years, the FAA has worked with Transport Canada, National Research Council Canada (NRC) and APS Aviation, Inc. to develop allowance times for aircraft operations in ice-pellet precipitation. These allowance times are critical to ensure safety and efficient operation of commercial and cargo flights. Wind-tunnel testing with uncontaminated anti-icing fluids and fluids contaminated with simulated ice pellets had been carried out at the NRC Propulsion and Icing Wind Tunnel (PIWT) to better understand the flowoff characteristics and resulting aerodynamic effects. The percent lift loss on the thin, high-performance wing model tested in the PIWT was determined at $8^{\circ}$ angle of attack and used as one of the evaluation criteria in determining the allowance times. Because it was unclear as to how performance degradations measured on this model were relevant to an actual airplane configuration, some means of interpreting the wing model lift loss was deemed necessary. This paper describes how the lift loss was related to the loss in maximum lift of a Boeing 737-200ADV airplane through the Aerodynamic Acceptance Test (AAT) performed for fluids qualification. A loss in maximum lift coefficient of 5.24 percent on the B737-200ADV airplane (which was adopted as the threshold in the AAT) corresponds to a lift loss of 7.3 percent on the PIWT model at $8^{\circ}$ angle of attack. There is significant scatter in the data used to develop the correlation related to varying effects of the anti-icing fluids that were tested and other factors. A statistical analysis indicated the upper limit of lift loss on the PIWT model was 9.2 percent. Therefore, for cases resulting in PIWT model lift loss from 7.3 to 9.2 percent, extra scrutiny of the visual observations is required in evaluating fluid performance with contamination.
\end{abstract}

\section{Nomenclature}

$C_{l} \quad$ sectional lift coefficient

$C_{L} \quad$ airplane lift coefficient

$C_{l, \text { max }} \quad$ maximum sectional lift coefficient

$C_{L, \max } \quad$ maximum airplane lift coefficient

$V_{2} \quad$ takeoff safety speed

$V_{s 1 g} \quad 1 g$ stall speed

$\alpha_{\mathrm{B}} \quad$ body angle of attack

$\alpha_{\mathrm{w}} \quad$ wing section angle of attack

$\delta^{*} \quad$ boundary-layer displacement thickness

$\delta^{*}$ fluid $\quad$ boundary-layer displacement thickness of fluid in AAT at a given temperature

$\delta^{*}{ }_{d r y} \quad$ boundary-layer displacement thickness of dry flat plate in AAT

$\delta^{*}{ }_{l @-20{ }^{\circ} \mathrm{C}}$ boundary-layer displacement thickness limit define for AAT at $-20{ }^{\circ} \mathrm{C}$

AAT Aerodynamic Acceptance Test

AMIL Anti-Icing Materials International Laboratory, Univ. of Quebec at Chicoutimi

APS APS Aviation, Inc. 


$\begin{array}{ll}\text { EG } & \text { ethylene glycol } \\ \text { FAA } & \text { Federal Aviation Administration } \\ \text { HOT } & \text { holdover time } \\ \text { IRT } & \text { Icing Research Tunnel } \\ \text { KEAS } & \text { equivalent airspeed, kn } \\ \text { NASA } & \text { National Aeronautics and Space Administration } \\ \text { NRC } & \text { National Research Council (Canada) } \\ \text { OAT } & \text { outside air temperature } \\ \text { PG } & \text { propylene glycol } \\ \text { PIWT } & \text { Propulsion and Icing Wind Tunnel } \\ \text { SEE } & \text { Standard Error of the Estimate }\end{array}$

\subsection{Introduction}

During the period from 1992 to 2004, many air carriers were allowed to operate in ice-pellet conditions provided that the flight crew did a contamination check of the wings within five minutes of takeoff although no holdover times (HOTs) existed for these conditions. This check was conducted from inside the aircraft in the case of most passenger aircraft, and from the outside for freighters (which had no windows in the cabin). This procedure for operation in ice-pellet conditions was incorporated into the deicing and anti-icing programs of many individual air carriers and approved annually by the FAA Principal Operations Inspector (POI) for those carriers.

In 2005, the FAA became concerned about operations in ice-pellet conditions after learning of questions raised relating to regional carriers operating in ice pellets with non-slatted aircraft and with less experienced flight crews than the major carriers. As a result of these concerns, the FAA issued three notices effectively disallowing operations in ice pellets in October 2005 (Refs. 1 to 3 In the winter of 2005 and 2006, this action had a major impact at several airports during ice-pellet events. Due in part to concerns raised by these events, the FAA undertook a thorough reassessment of its policy with respect to operation in ice-pellet conditions.

HOTs are determined based on the results of endurance time testing of anti-icing fluids in natural or simulated icing conditions. Fluid failure occurs when the fluid is no longer able to effectively absorb the incoming precipitation. The endurance times are determined by applying failure criteria using visual cues for fluid failure, which vary depending on the icing conditions (snow, freezing drizzle, freezing rain).

Environmental chamber testing showed that ice pellets generally remain in the frozen state imbedded in Type IV anti-icing fluid, and are not absorbed by the fluid in the same manner as other forms of precipitation. Using the guidelines for determining anti-icing fluid failure, the presence of a contaminant not absorbed by the fluid (remaining imbedded) would be an indication that the fluid has failed. However, the imbedded ice pellets were generally not readily detectable by the human eye except through short range inspection. This indicated that a contamination check of the wings within five minutes of takeoff in operational conditions would be of little value. The difficulty in establishing visual cues for detecting fluid failure in ice-pellet conditions has thus far precluded the establishment of practical failure criteria for endurance time testing. Without endurance time testing, HOTs cannot be established and so the FAA has never provided HOTs for operations in ice-pellet conditions.

The environmental chamber testing did not indicate that the imbedded ice pellets were conducive to contamination adhering to the underlying surface. Researchers decided to examine whether this was also true during actual takeoff runs, and also whether the presence of the ice pellets somehow interfered with the flowoff of the fluid during a takeoff run. Adhering contamination or a significant amount of fluid remaining on the wing at takeoff would both represent a safety hazard.

Beginning in March 2006 and continuing in subsequent years, the FAA Ground Icing Program and Transport Canada sponsored aircraft-based and wind-tunnel based research to better determine allowance times associated with operations in ice-pellet conditions. Broeren and Riley (Ref. 4) provide a more detailed summary of this research along with a description of the resulting ice-pellet allowance time 
tables. An allowance time differs from a HOT in that there is no provision for pre-takeoff contamination check if the time is exceeded, meaning that the allowance time cannot be extended by a visual cabin check or external tactile or visual check of the aircraft critical surfaces within 5 min of takeoff. Ordinarily pre-takeoff contamination checks are conducted from the cabin, and the research showed that such a check would be of little use in the case of ice pellets (Ref. 5) A recent example allowance times table is shown in Table I.

TABLE I.-ICE PELLET ALLOWANCE TIMES FOR WINTER 2010-2011 (REF. 12)

\begin{tabular}{|c|c|c|c|}
\hline & $\begin{array}{c}\text { OAT }-5^{\circ} \mathrm{C} \\
\text { and above, } \\
\text { min }\end{array}$ & $\begin{array}{l}\text { OAT less than } \\
-5 \text { to }-10^{\circ} \mathrm{C}, \\
\text { min }\end{array}$ & $\begin{array}{c}\text { OAT less than } \\
-10{ }^{\circ} \mathrm{C} \\
\text { min }\end{array}$ \\
\hline Light ice pellets & 50 & 30 & $30^{\mathrm{a}}$ \\
\hline Moderate ice pellets & $25^{\mathrm{b}}$ & 10 & $10^{\mathrm{a}}$ \\
\hline Light ice pellets mixed with light or moderate freezing drizzle & 25 & 10 & \multirow{6}{*}{$\begin{array}{l}\text { Caution: No allowance } \\
\text { times currently exist }\end{array}$} \\
\hline Light ice pellets mixed with light freezing rain & 25 & 10 & \\
\hline Light ice pellets mixed with light rain ${ }^{\mathrm{c}}$ & 25 & & \\
\hline Light ice pellets mixed with moderate rain $^{\mathrm{c}}$ & 25 & & \\
\hline Light ice pellets mixed with light snow & 25 & 15 & \\
\hline Light ice pellets mixed with moderate snow & 10 & & \\
\hline
\end{tabular}

${ }^{a}$ No allowance times exist for PG fluids, when used on aircraft with rotation speeds less than $115 \mathrm{kn}$. (For these aircraft, if the fluid type is not known, assume zero allowance time.)

${ }^{\mathrm{b}}$ Allowance time is $15 \mathrm{~min}$ for PG fluids, or when the fluid type is unknown.

'Operations NOT authorized below $0{ }^{\circ} \mathrm{C}$

Ice pellets often occur mixed with other forms of precipitation in North America (Ref. 6) Thus the FAA recognized a need for further testing for various mixed conditions and temperature ranges. During January-February 2007, in cooperation with Transport Canada, ice-pellet contamination testing was conducted in a large, open-circuit wind tunnel. This facility, the Propulsion and Icing Wind Tunnel (PIWT) is owned and operated by NRC. APS Aviation, Inc. was contracted to support this research. Ice pellets were simulated using crushed ice from blenders which was run through sieves to get a size distribution similar to natural ice pellets. A two-dimensional, single element, NACA 23012 airfoil model with $4.0 \mathrm{ft}(1.2 \mathrm{~m})$ chord was used for this test campaign (Ref. 7) An airplane takeoff acceleration profile and rotation was simulated in the wind-tunnel testing typically reaching a maximum speed of $100 \mathrm{kn}$ $(51.4 \mathrm{~m} / \mathrm{s})$ in 30 to $35 \mathrm{sec}$. Allowance times were determined using the visual observations of the researchers. Limited aerodynamic measurements were also made, supplementing the observations of the researchers. However, the results did not show large effects of the contaminated fluids on the lift coefficient, and no aerodynamic criteria were introduced for the determination of allowance times. The PIWT tests were also supplemented by environmental chamber tests whereby plates contaminated with ice pellets were subjected to simulated freezing rain, freezing drizzle, and snow. Based on the results from the testing, the FAA published an allowance time table for winter 2007-2008 in Notice N 8900.19 (Ref. 8) and also in Notice N 8900.22 (Ref. 9).

In January and March 2009 wind-tunnel testing was again conducted at the NRC PIWT using a $6.0 \mathrm{ft}$ $(1.8 \mathrm{~m})$ chord LS(1)-0417 airfoil model. This model had a span of $7.9 \mathrm{ft}(2.4 \mathrm{~m})$ and was mounted in the tunnel between two end plates to minimize three-dimensional (3-D) effects. This model had a singleelement slotted flap deployed at $15^{\circ}$. Allowance times were again determined primarily using the visual observations of the researchers. Aerodynamic measurements were made, supplementing the observations of the researchers. However, the results did not show large effects of the contaminated fluids (never more than 5 percent loss of lift), and no aerodynamic criteria were explicitly introduced for the determination of allowance times. Based on the results, the FAA published an updated ice-pellet allowance time table for Winter 2009-2010 in Notice N 8900.98 (Ref. 10).

Tests were continued in the NRC PIWT in January and February 2010 using a thin, high-performance airfoil model rigged with a single-element slotted flap fixed at $20^{\circ}$. The thin, high-performance section was regarded as typical of wings on regional jet transport airplanes. This model had a chord of $6.0 \mathrm{ft}$ 
$(1.8 \mathrm{~m})$ and a span of $7.9 \mathrm{ft}(2.4 \mathrm{~m})$ and was mounted in the tunnel between two end plates. Clark and MacMaster (Ref. 11) provide further information regarding the January and February 2010 wind-tunnel testing conducted at the NRC PIWT. Aerodynamic measurements were again made, and effects on lift were significantly larger than in past years. Along with visual evaluation by the researchers, a criterion for percentage loss in lift at $8^{\circ}$ angle of attack was explicitly used in developing allowance times. This raised several concerns that are discussed in detail in Section 4.0 of this paper. Based on the results, the FAA published an updated ice pellet allowance time table for winter 2010-2011 and 2011-2012, on the FAA AFS-200 Ground Deicing Web site (Ref. 12) reproduced here as Table I. Tests were continued in the NRC PIWT in January-February 2011 using the same thin, high-performance wing model used the previous year. There were no changes to the allowance times tables for winter 2011-2012 based on the testing.

The dissemination of the wind-tunnel testing results and subsequent changes to the ice-pellet allowance time tables have led to concerns regarding the fidelity and applicability of the measured lift degradation in the ice-pellet contamination fluid testing at the NRC PIWT. Given the potential operational safety implications associated with the measured performance degradations, it is even more important that these concerns be addressed appropriately. The essence of these concerns is understanding how the performance degradations measured on the model in the NRC PIWT testing relate to an actual three-dimensional, full-scale airplane configuration. Therefore, some means of determining the significance of the measured lift degradations relative to a full-scale airplane is necessary.

It has been suggested that the measured lift degradation due to the uncontaminated fluids in the NRC PIWT tests could be compared to the loss in maximum lift that is associated with the Aerodynamic Acceptance Test (AAT). The AAT is described in SAE Aerospace Standard AS5900 (Ref. 13) and was developed as a means to qualify deicing and anti-icing fluids. The purpose of this paper is to briefly review the research basis of the AAT (Section 2.0) and determine how it may be applied to the present aerodynamic testing of anti-icing fluids in the PIWT. Broeren and Riley (Ref. 4) offer a more detailed review of the research basis of the AAT that is beyond the scope of this paper. Section 3.0 then provides a review of the anti-icing fluid aerodynamic testing conducted at the NRC PIWT with uncontaminated fluids. These results were used in conjunction with results from the AAT performed for the same fluids to relate the aerodynamic degradation on the two-dimensional (2-D) PIWT model to a B737-200ADV airplane. This relationship was then used to develop a lift loss criterion that could be used establish allowance times for ice-pellet contamination. Section 4.0 describes how this "scaling" method may address the concerns raised in regard to the NRC PIWT test methods and implications for establishing ice-pellet allowance times.

\subsection{Review of the Research Basis of the Aerodynamic Acceptance Test}

A major research program was conducted in the mid to late 1980s and early 1990 s to characterize deicing/anti-icing fluid behavior and aerodynamic effects on transport airplanes. This work was led by Eugene Hill and Thomas Zierten of the Boeing Commercial Airplane Group and is described in (Ref. 14 to 17. This research led to the development of the AAT that is described in Reference 13. A flight test campaign was conducted to establish the fluid effects on a full-scale Boeing 737-200ADV airplane. Following the flight test, wind-tunnel testing was conducted with both 3-D and 2-D subscale models based upon the B737-200ADV in the NASA Glenn (then Lewis) Icing Research Tunnel (IRT). The icing tunnel test results were correlated to the flight trials to determine the applicability of subscale wind-tunnel testing for deicing/anti-icing fluid effects. The IRT testing was extended to include boundary-layer measurements on the 2-D model. These measurements were subsequently correlated to boundary-layer measurements on a flat plate model in a small-scale wind tunnel to form the basic principles of the AAT. 


\subsection{Flight and IRT Test Campaigns}

The flight test campaign was conducted during January 11 to 20, 1988, at Kuopio, Finland. The experiments were led by Boeing and supported by the Association of European Airlines (AEA) and three fluid manufacturers. The objectives were to evaluate the aerodynamic effects of the fluids on the B737200ADV airplane to establish a full-scale database. Overall, the flight test results showed that the lift is lower with the fluids applied to the wing relative to the clean, dry baseline. The fluid effects on lift coefficient were determined for a liftoff attitude of $12^{\circ}$ which was typical of the one-engine inoperative takeoff climb attitude for the B737-200ADV (Ref. 14). The baseline lift coefficient for $\alpha_{B}=12^{\circ}$ corresponded to 75 percent of $C_{L, \text { max }}$ for the clean, dry airplane. Flight test data were not gathered near $C_{L, \max }$ because this would have required stalling the airplane close to the ground (Ref. 17). Percent lift losses ranged from 2 percent to 7 percent for four fluids at various temperatures from -10 to $-2{ }^{\circ} \mathrm{C}$ and for both the flaps 5 and flaps 15 configurations. In general, the lift penalties due to the fluid were higher at flaps 15 than flaps 5, thus illustrating the effect of airplane configuration. Hill and Zierten (Ref. 14) reported other important conclusions from the B737-200ADV flight test trials.

The two IRT test campaigns were cooperative efforts among Boeing who provided the models and conducted the test, NASA Glenn who provided use of the IRT and test support, various fluid manufacturers who provided the deicing/anti-icing fluids and the AEA who monitored the test to maintain continuity with their fluids research program at that time. The first IRT test campaign, Phase I, was conducted in early 1988, shortly after the conclusion of the flight test trials. According to Hill and Zierten (Ref. 14), the primary objective of the Phase I test campaign was to validate the use of wind-tunnel tests for investigating the aerodynamic effects of deicing/anti-icing fluids. The Phase I IRT campaign was conducted using an existing B737-200ADV model. This model was a 9.1 percent scale, 3-D half-plane model mounted to a splitter wall along the tunnel test-section sidewall. The average chord length for this model was $1.0 \mathrm{ft}(0.305 \mathrm{~m})$ and the wing was equipped with a leading-edge slat and a trailing-edge flap. The model was tested with and without a ground plane installed in the test section. Through the course of the initial IRT investigations, variations in the time to rotation, rotation speed and rotation rate were evaluated. It was determined that use of values identical to the flight test campaign was appropriate for the subscale model tests (Ref. 17) Hill and Zierten (Ref. 14) concluded that the subscale model lift loss results due to the fluids could be extrapolated to full scale on a one-to-one basis. The authors also mentioned that similar results have been observed with distributed solid roughness on the wing further supporting this conclusion. The subscale model lift coefficient was evaluated at $\alpha_{\mathrm{B}}=7^{\circ}$ as this corresponded to 75 percent of $C_{L, \text { max }}$ for the clean, dry, 9.1 percent scale, 3-D half-plane model.

Having addressed the validity of the IRT testing with the 3-D half-plane model in Phase I, the test objectives were expanded in Phase II to include determining the effects of the fluids on maximum lift coefficient and acquisition of boundary-layer displacement thickness data that were subsequently used in the development of the AAT. Further tests were conducted with the 9.1 percent scale, 3-D half-plane model described in the previous paragraph. In addition, a 2-D model test set up was also introduced into the IRT test section. The $2-\mathrm{D}$ model was an 18 percent scale $(1.5 \mathrm{ft}(0.457 \mathrm{~m})$ chord $)$ section of the B737$200 \mathrm{ADV}$ wing at 65 percent semispan station. It was mounted horizontally between two splitter walls and no ground plane was used. This section (at 65 percent semispan) was selected because it was "critical" relative to the stall progression on the baseline, clean, full-scale B737-200ADV airplane. The boundarylayer velocity profile was measured with a pressure rake mounted toward the aft end of the model, just upstream of the flap. The velocity profile was integrated to obtain the boundary-layer displacement thickness. These measurements were performed at $\alpha_{\mathrm{w}}=8^{\circ}$ which directly corresponded to $\alpha_{\mathrm{B}}=7^{\circ}$ on the 3-D half-plane model. 
Through the course of these, and previous, investigations hypotheses relating the fluid-flow-off behavior to the aerodynamic degradation were being developed and tested. It is beyond the scope of this paper to describe these hypotheses, related experiments and observations with the exception of the hypothesis leading to the development of the AAT. Hill and Zierten (Ref. 14) suggested, "If the hypothesis is valid that the mechanism of the fluid effect on the aerodynamics of the wing is premature growth of the boundary layer, then a correlation between the prematurely thickened boundary layer and the aerodynamic effect can be anticipated." Their hypothesis was supported by Figure 1 that illustrates the suggested correlation between the percent lift loss on the 2-D model at $\alpha_{\mathrm{w}}=8^{\circ}$ and $\delta^{*}$ measured on the same model at the same condition. Since the data for the various fluids and air temperatures "collapse" onto the correlation curve, the conclusion is that the hypothesis is valid. Hill and Zierten continue: "Because the two-dimensional model airfoil is the critical (relative to stall progression) 737$200 \mathrm{ADV}$ wing section and assuming that the thickened boundary-layer measured at 8-deg. angle of attack was an indicator of the effect of fluid at maximum lift, then an acceptable correlation between the twodimensional model boundary-layer thickness and the three-dimensional model maximum lift loss can also be anticipated." The suggested correlation is shown in Figure 2 that plots the 3-D model percent loss in maximum lift against $\delta^{*}$ measured on the $2-\mathrm{D}$ airfoil model at $\alpha_{\mathrm{w}}=8^{\circ}$ for the same fluids at the same conditions used on each model. All of the data for the various fluids at three different temperatures tend to collapse onto the curve shown in Figure 2, suggesting that the correlation is, as suggested, acceptable. Therefore, Hill and Zierten concluded that these results indicate that the fluid effects on the boundarylayer thickness (on the 2-D model at $\alpha_{\mathrm{w}}=8^{\circ}$ ) is an indicator of fluid effects on airplane performance.

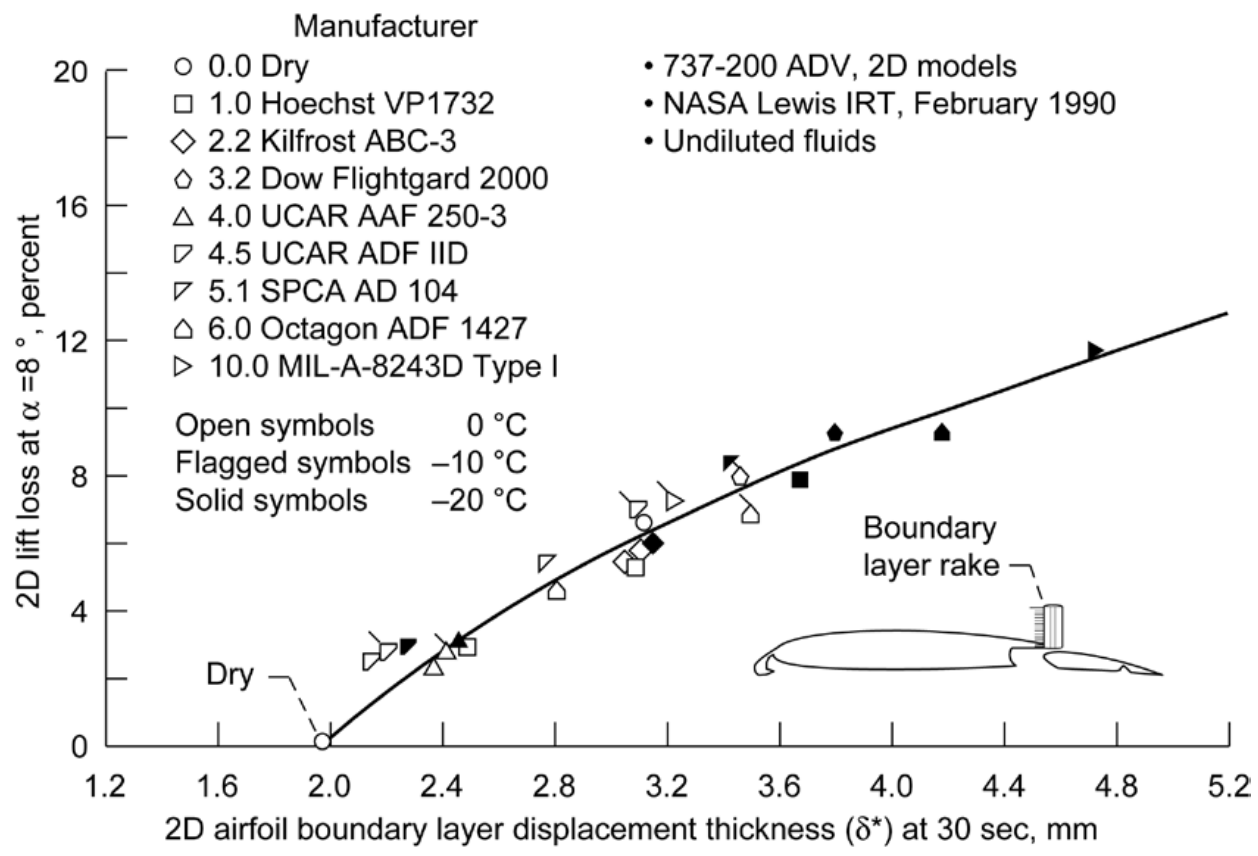

Figure 1.-Correlation between percent lift loss and boundary-layer displacement thickness as measured on the 2-D model at $\alpha_{w}=8^{\circ}$ for various fluids at air temperatures of $0,-10$ and $-20{ }^{\circ} \mathrm{C}$, after Hill and Zierten (Ref. 14). 


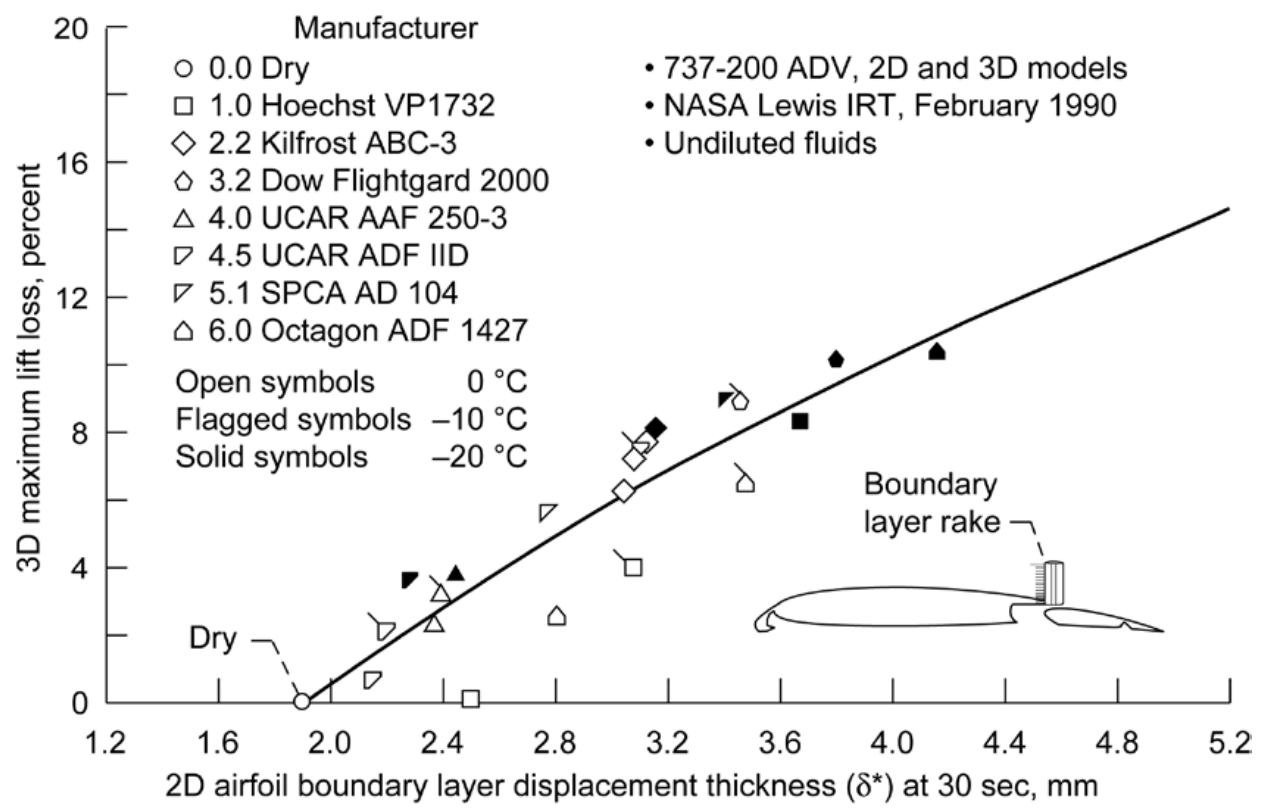

Figure 2.-Correlation between 3-D B737-200ADV model percent maximum lift loss and 2-D model boundary-layer displacement thickness at $\alpha_{w}=8^{\circ}$ for various fluids at air temperatures of $0,-10$ and $-20^{\circ} \mathrm{C}$, after Hill and Zierten (Ref. 14).

These correlations and the data plotted in Figure 1 and Figure 2 imply a direct relationship between the percent maximum lift loss measured on the 3-D model and the percent lift loss measured at $\alpha_{\mathrm{w}}=8^{\circ}$ on the 2-D model for the same fluids tested on each model under identical conditions. These data were extracted from Figure 1 and Figure 2 and are plotted in Figure 3. This could be done because the $\delta^{*}$ data plotted on the horizontal axis was common to both plots. In Figure 1, a measured value of $\delta^{*}$ for a given fluid at a given temperature was associated with a percent lift loss on the 2-D model at $\alpha_{\mathrm{w}}=8^{\circ}$. The same fluid at the same temperature was tested on the 3-D model as well, providing a specific percent loss in maximum lift. Thus, the same $\delta^{*}$ measured in the 2-D test for the same fluid at the same temperature was correlated with percent maximum lift loss on the 3-D model, even though $\delta^{*}$ was not measured on the 3$\mathrm{D}$ model. The resulting correlation is shown in Figure 3 and a linear fit was constructed through the data. The $y$-intercept was forced through the origin because this is the limiting case for the dry wing. That is, the dry wing has no lift loss for either the 2-D or 3-D model, by definition. The slope of the line, 1.04, is very close to one which is consistent with the statement by Hill and Zierten that the 2-D wing section tested was the critical section relative to the stall progression. The data show that the implied correlation between the lift loss on the 2-D model at $\alpha_{\mathrm{w}}=8^{\circ}$ and the maximum lift loss on the 3-D model was better for some fluids than for others. Note that there are three data points for each fluid corresponding to air temperatures of $0,-10$, and $-20^{\circ} \mathrm{C}$ as in Figure 1 and Figure 2. Generally, the percent lift loss increases with decreasing temperature. The data for the Dow, UCAR AAF and SPCA fluids tend to match the correlation fairly well, whereas the data for the Hoeschst and Kilfrost fluids clearly had a different effect between the 2-D and 3-D models. This same "scatter" is represented in Figure 1 and Figure 2, however, the discrepancies do not appear to be as large due to the choice of scales on the plots. These data illustrate the potential variation in fluid behavior and their attendant effects on aerodynamic performance. 


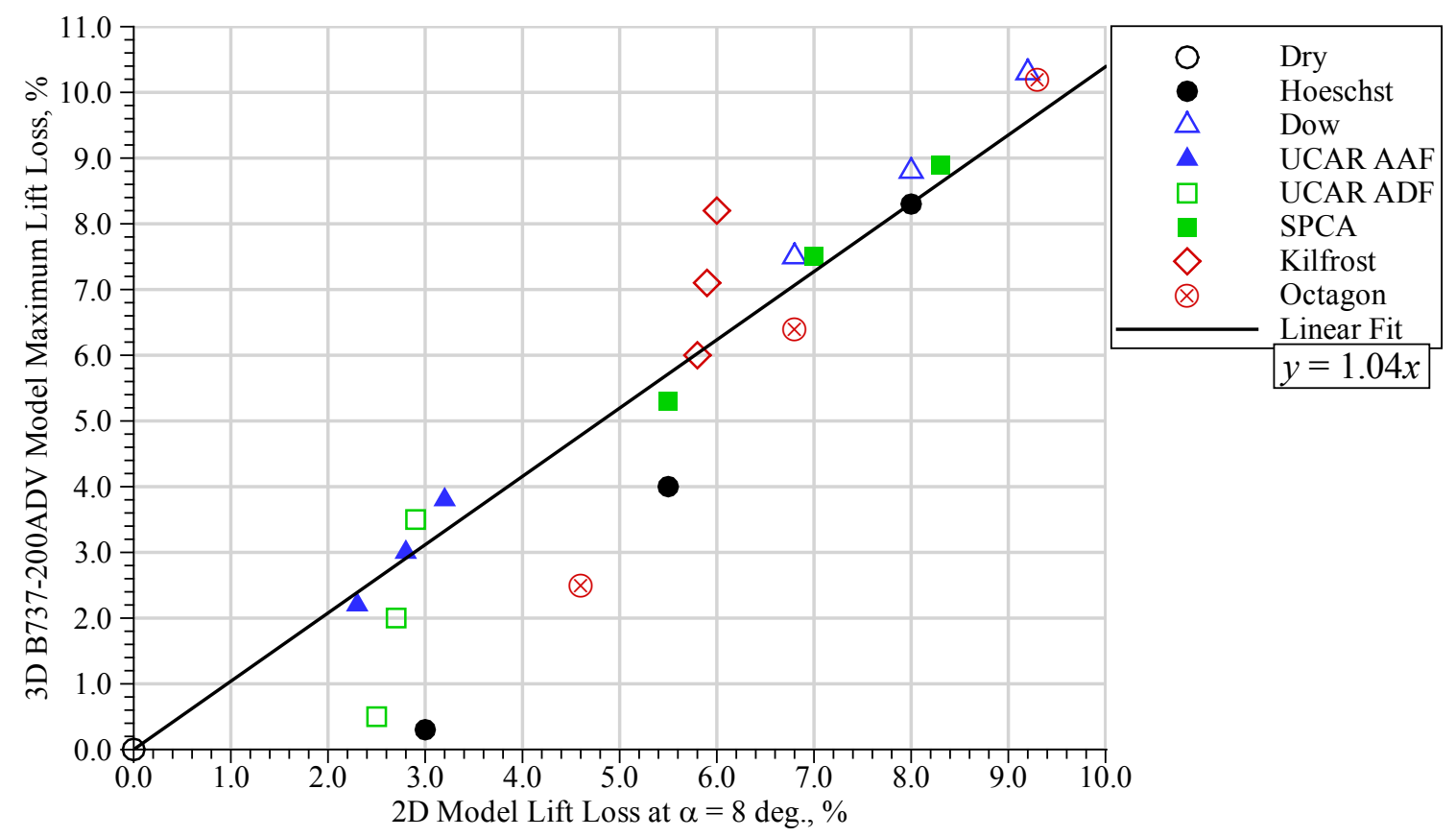

Figure 3.-Correlation between percent lift loss on the 2-D model at $\alpha_{w}=8^{\circ}$ and percent maximum lift loss on the 3-D B737-200ADV model for a given fluid at a given temperature in the Phase II IRT tests. Note that there are three data points for each fluid representing $0,-10$ and $-20^{\circ} \mathrm{C}$. Data extracted from Hill (Ref. 15).

\subsection{Basis of the AAT}

The research and findings regarding the potential transitory aerodynamic degradation due to fluids led an international working group to develop the AAT for the fluids. This working group was formed under the Aerospace Industries of America Transportation Committee and consisted of industry representatives and others members. This AIA TC 218-4 group worked with the von Kármán Institute and the AEA to develop the AAT. Research performed at the von Kármán Institute showed that the fluid flowoff behavior on a flat plate in a small-scale wind tunnel capable of operational airspeeds and temperatures correlated to the flowoff characteristics observed on the 2-D B737-200ADV wing section tested in the NASA IRT. This correlation, plotted in Figure 4, suggests a quasi-linear relationship between the displacement thickness measured on the 2-D airfoil model and the flat plate testing that was conducted at the von Kármán Institute.

The series of correlations presented in Figure 1, Figure 2 and Figure 4 imply that there exists a final correlation between the maximum lift loss measured on the 9.1 percent scale 3-D B737-200ADV halfplane model in the IRT and the boundary-layer displacement thickness measured on the flat plate. This final correlation is shown as a linear relationship in Figure 5. To summarize, this correlation was developed through the following steps:

- Takeoff profile flight tests were performed on a B737-200ADV airplane to measure the effects of the fluid on lift. This was specifically documented at $\alpha_{\mathrm{B}}=12^{\circ}$, corresponding to 75 percent of $C_{L, \max }$ on the clean, dry airplane.

- Subsequent tests performed in the NASA IRT on a 9.1 percent scale, 3-D B737-200ADV half-plane model using the same fluids and temperatures as in the flight tests showed that percentage lift losses at 75 percent $C_{L, \max }$ (corresponding to $\alpha_{\mathrm{B}}=7^{\circ}$ on the subscale model) could be extrapolated to full scale on a one-to-one basis. 
- Furthermore, aerodynamic testing on subscale models and flight tests with simulated roughness and frost indicated that the percent maximum lift losses (i.e., $\Delta C_{L, \max }$ ) measured on the 9.1 percent scale 3-D B737-200ADV half-plane model could also be extrapolated to full-scale on a one-to-one basis.

- Therefore, the effect of fluids on full-scale airplane maximum lift was determined directly from IRT tests conducted on the 9.1 percent scale 3-D B737-200ADV half-plane model.

- $\quad$ IRT tests performed with the same fluids and temperatures on the 18 percent scale 2-D B737-

200ADV wing section model showed that percent lift losses measured at $\alpha_{\mathrm{w}}=8^{\circ}$ correlated with:

$\circ$ boundary-layer displacement thickness on the 18 percent scale 2-D B737-200ADV wing section at $\alpha_{\mathrm{w}}=8^{\circ}$ (Figure 1)

$\circ$ percent maximum lift loss on the 9.1 percent scale 3-D B737-200ADV half-plane model correlated with the boundary-layer displacement thickness on the 18 percent scale 2-D B737200ADV wing at $\alpha_{\mathrm{w}}=8^{\circ}$ (Figure 2).

$\circ$ percent maximum lift loss on the 9.1 percent scale 3-D B737-200ADV half-plane model (Figure $3)$.

- The displacement thickness measured on a flat plate in a small-scale, refrigerated wind tunnel at the von Kármán Institute with the same fluids and temperatures correlated with the displacement thickness measured on the 18 percent scale 2-D B737-200ADV wing section at $\alpha_{w}=8^{\circ}$ (Figure 4).

- Therefore, the percent maximum lift losses on the full-scale B737-200ADV airplane correlated with the displacement thickness measured on the flat plate (Figure 5).

This summarizes the development of the AAT for deicing/anti-icing fluids. The research showed that it was possible to conduct meaningful small-scale, flat-plate experiments to evaluate the potential aerodynamic effects of these fluids. The remaining step in the development of the AAT was to establish the acceptance criterion.

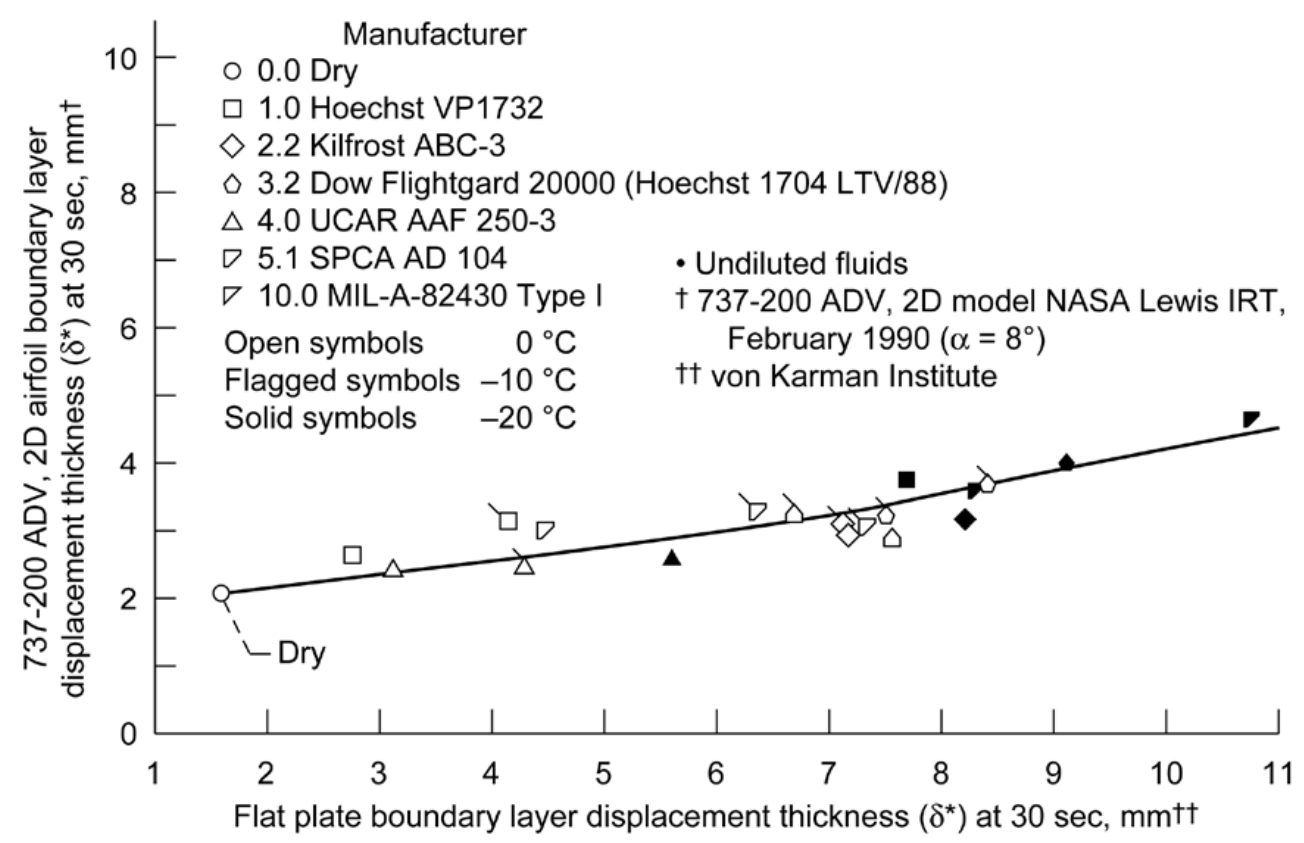

Figure 4.-Correlation between displacement thickness measured on the 2-D B737200ADV wing section in the IRT and the displacement thickness measured on the flat plate in the von Kármán Institute experiment, after Hill and Zierten (Ref. 14). 


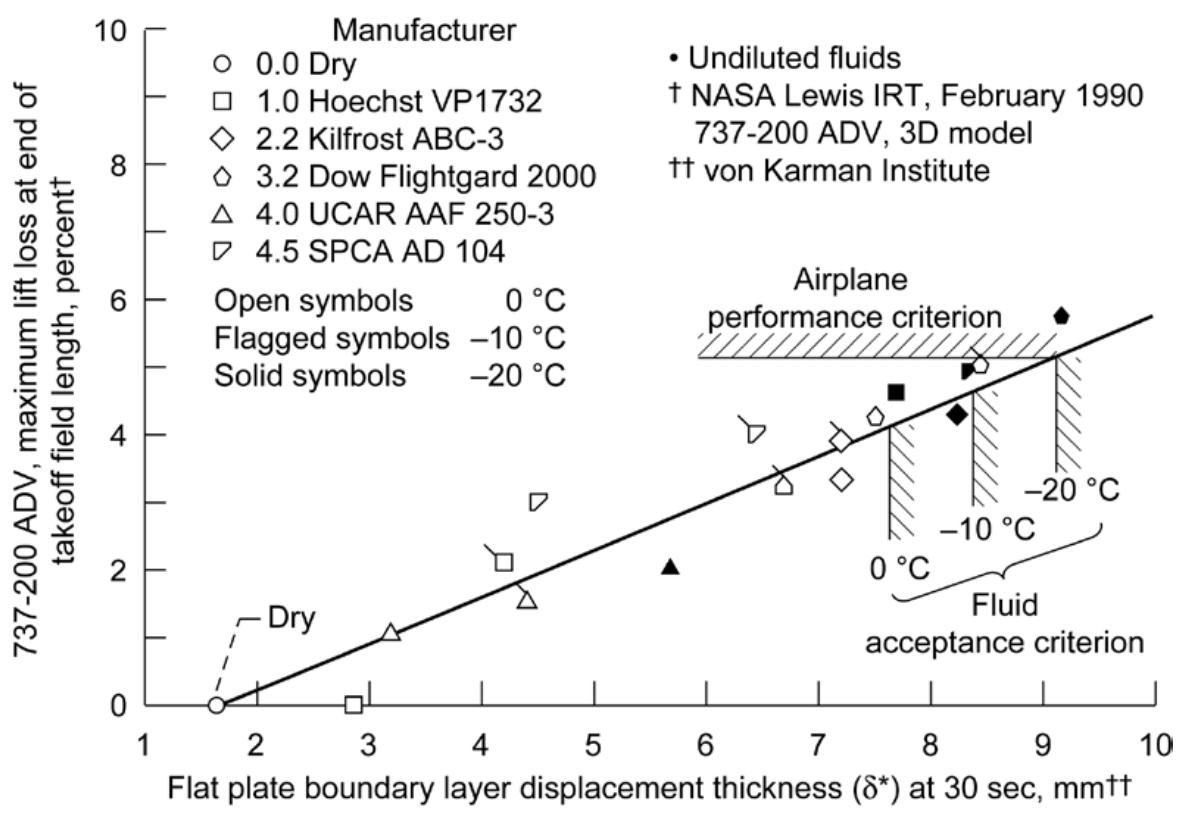

Figure 5.-Correlation between maximum lift loss on the full-scale B737-200ADV airplane and the displacement thickness measured on the flat plate at von Kármán Institute, after Hill and Zierten (Ref. 14).

\subsection{Fluid Acceptance Criterion}

Hill and Zierten (Ref. 14) considered several takeoff performance criteria that were important to safe operations with deicing/anti-icing fluids. They determined that the most critical was ensuring adequate margin between the $1 g$ stall speed $\left(V_{s 1 g}\right)$ and the takeoff safety speed $\left(V_{2}\right)$. A reduction in airplane maximum lift coefficient $\left(\Delta C_{L, \text { max }}\right)$ equal to 5.24 percent was established by requiring the $V_{2}$ speed to be at least 10 percent higher than $V_{s 1 g}$ compared to the 13 percent margin for the clean, dry wing. Of course, this requirement is specific to the B737-200ADV used in the AAT development research. There is reduced concern for airplanes with larger margin for the $V_{2}$ speed. The 5.24 percent maximum lift loss criterion is shown in Figure 5 as the upper limit in lift loss and corresponding boundary-layer displacement thickness measured in the flat-plate experiment at von Kármán Institute. The plot shows that the 5.24 percent cut-off correlates $\delta^{*} \approx 9.2 \mathrm{~mm}$ for the fluid at $-20{ }^{\circ} \mathrm{C}$. Figure 5 also indicates that there were slightly lower maximum lift loss criteria for temperatures of -10 and $0{ }^{\circ} \mathrm{C}$. Hill and Zierten (Ref. 14) explained that this was imposed because runways would be more likely to be contaminated at these warmer temperatures. Presumably the contaminated runways would also have an adverse impact on the airplane performance in addition to the presence of the deicing/anti-icing fluid. While this may be an important consideration for the AAT, it is important to realize the that reduced acceptance criteria (either in terms of $\Delta C_{L, \max }$ or $\delta^{*}$ ) was not based upon a fluid-specific requirement, but concerns about additional adverse effects due to contaminated runways.

This brief review of the research basis of the AAT has shown how the potential adverse performance effects of deicing/anti-icing fluids on a B737-200ADV airplane were related to the boundary-layer displacement thickness measured on a flat plate. The relatively simple and low-cost flat-plate experiment has subsequently been used as a part of the qualification process for ground deicing/anti-icing fluids. Hill and Zierten have noted many times in their work that the aerodynamic effects of these fluids are configuration dependent and can be influenced by other factors such as the takeoff speed. The reader is referred to the more detailed summary by Broeren and Riley (Ref. 4) or to the original References 14 to 17 , for further information. 


\subsection{Aerodynamic Evaluation of Anti-Icing Fluids in the NRC PIWT}

\subsection{Introduction}

As described in Section 1.0, a cooperative effort among FAA, Transport Canada, APS and NRC has been undertaken to develop allowance times for ice-pellet conditions. The aerodynamic testing of the fluids with and without contamination was conducted at the PIWT facility on the NRC Montreal Road campus in Ottawa. One of the criteria used to evaluate the effectiveness of the fluid protection is the lift loss caused by the fluid/contamination as measured in the wind tunnel. The use of a lift loss performance criterion requires the establishment of some threshold value above which some safety level would be exceeded. (Such a threshold was developed for the AAT as described in Section 2.0.) Since the testing has employed a generic, thin, high-performance wing section, it is unclear what the appropriate lift loss threshold should be. Some means of relating the wind-tunnel model lift degradation to a real airplane configuration is needed in order to determine a reasonable lift loss threshold. This is important because of the potential operational safety implications associated with the measured performance degradations due to contaminated fluids.

It has been suggested that the measured lift loss due to the uncontaminated fluid in the PIWT tests can be compared to the B737-200ADV lift loss that is related to the AAT (as will be explained in this section). This approach provides a means to "scale" the measured lift degradation in the PIWT tests to equivalent maximum lift degradation on a full-scale B737-200ADV airplane. As reviewed in Section 2.0, Hill and Zierten (Ref. 14) showed that 2-D airfoil percent lift loss and boundary-layer displacement thickness correlated with the 3-D model maximum lift loss. Therefore, the thin, high-performance PIWT wing model lift loss may be correlated with the AAT results for tests with the same uncontaminated fluids at the same temperatures. Since the AAT results are directly related to percent maximum lift loss on the B737-200ADV airplane, this correlation can be applied to establish an equivalent lift loss threshold for the thin, high-performance wing model used in the NRC PIWT tests.

The purpose of this section is to demonstrate how this correlation analysis was carried out. Samples of the fluids used during the 2010 and 2011 PIWT test campaigns were subjected to the AAT as described in Reference 13 at the University of Quebec at Chicoutimi Anti-Icing Materials International Laboratory (AMIL). The AAT was performed over temperature ranges that closely matched those used in the PIWT test campaigns. For each fluid, the boundary-layer displacement thickness variation with temperature was quantified according to the Reference 13 procedures. An analysis was then performed to determine the relationship between the measured AAT boundary-layer displacement thickness, the PIWT model percent lift degradation for the fluid and the corresponding percent maximum lift loss on the B737-200ADV airplane. This analysis was used to define a lift loss threshold for evaluating the fluid performance on the model in the PIWT test. This procedure and results are described in the Sections 3.3, 3.4 and 3.5. The experimental methods used in the PIWT tests are described first in Section 3.2.

\section{2 $\quad$ PIWT Test Experimental Methods}

The experimental methods used to evaluate the performance of fluids in their uncontaminated state and with ice-pellet contamination has been described elsewhere, so only a brief overview is given here. For example, Clark and MacMaster (Refs. 18 and 19) provide a detailed description of the test set up, procedures and results. The PIWT is an open-return wind tunnel that draws air from the outdoors and is therefore naturally cooled. The fan is located in the wind-tunnel inlet and was driven by a gas turbine engine for these test campaigns. The test section measures $10 \mathrm{ft}(3 \mathrm{~m})$ across and $20 \mathrm{ft}(6 \mathrm{~m})$ in height. For these tests an insert was used that reduced the height to $16.4 \mathrm{ft}(5 \mathrm{~m})$ resulting in an increase in maximum test section speed. A 2-D airfoil section was mounted horizontally in the test section as shown in Figure 6. The model had a span of $7.9 \mathrm{ft}(2.4 \mathrm{~m})$ and was isolated from the wind-tunnel walls with endplates. Due to the large gaps between the endplates and the test-section walls $(\approx 1 \mathrm{ft}(0.3 \mathrm{~m})$ on each side) and the 

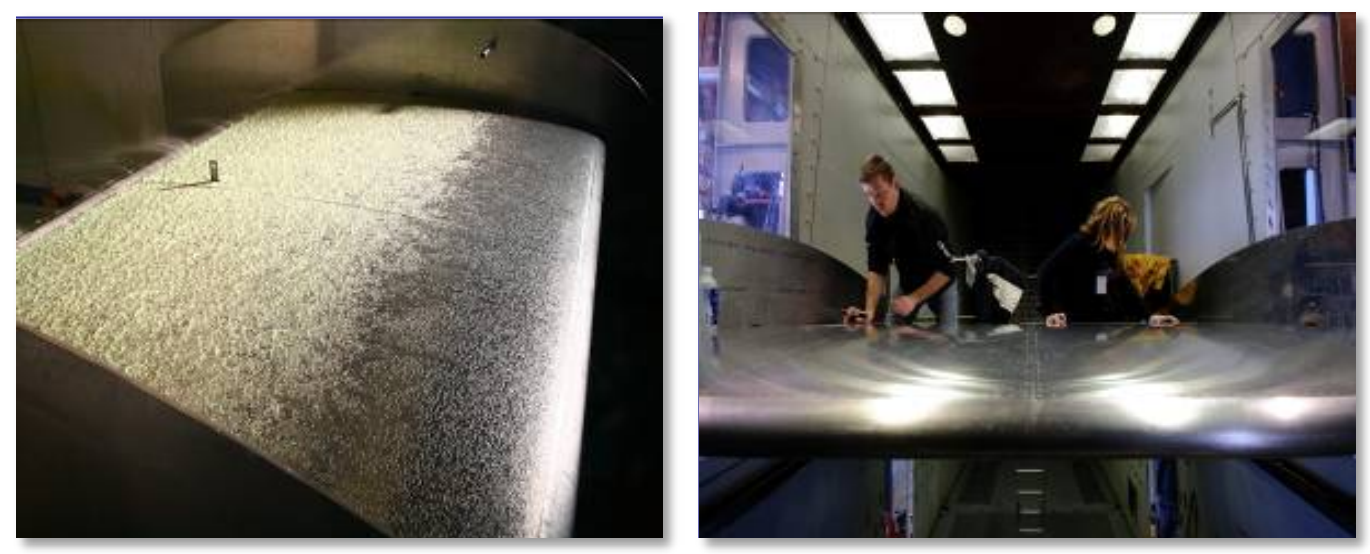

Figure 6.-Photographs of thin, high-performance wing model installed in the NRC PIWT facility.

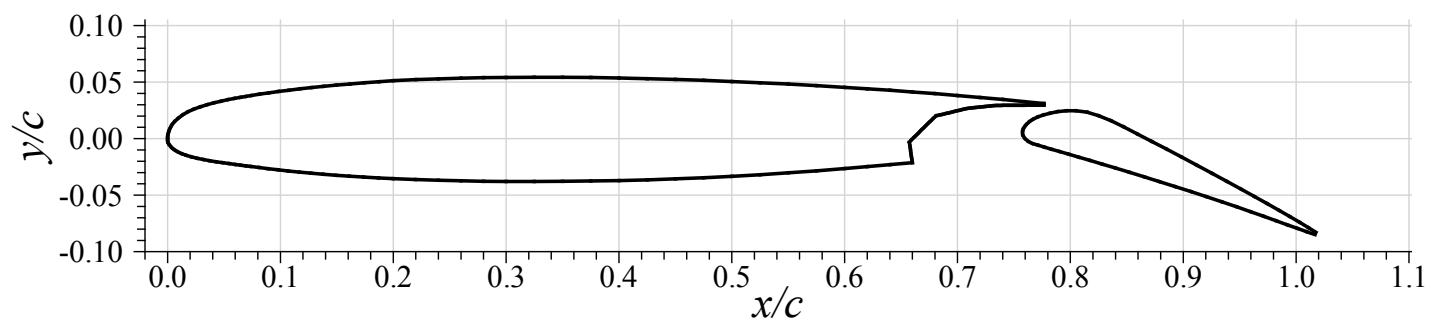

Figure 7.-Thin, high-performance airfoil section used in the PIWT testing, reference chord $=6.0 \mathrm{ft}(1.8 \mathrm{~m})$.

small size of the end plates, the model installation is quasi-two-dimensional. Figure 7 shows the $6 \mathrm{ft}$ (1.8 $\mathrm{m})$ chord, thin, high-performance wing section with single-slotted flap deflected at $20^{\circ}$. The model had a fixed (or "hard") leading edge and was regarded as typical of wings on regional jet transport airplanes. The model was supported by a force balance at each end located outside of the test-section walls. A drive motor and gearbox connected to the force balance provided rotation for setting angle of attack. The lift data and angle of attack were corrected for wind-tunnel wall effects using the 2-D airfoil methods described in Rae and Pope (Ref. 20).

Data from a typical simulated takeoff run are shown in Figure 8. Plotted is the model lift coefficient versus time. These data were acquired by accelerating the test section airflow from $20 \mathrm{kn}(10.3 \mathrm{~m} / \mathrm{s})$ to 100 $\mathrm{kn}(51.4 \mathrm{~m} / \mathrm{s})$ in less than $31 \mathrm{sec}$. In a typical profile, the model was rotated from $\alpha_{\mathrm{w}}=-2^{\circ}$ to $8^{\circ}$ at a rotation rate of $2.7^{\circ} / \mathrm{sec}$. after the air speed reached $100 \mathrm{kn}$. The wing was held at $8^{\circ}$ for $1.5 \mathrm{sec}$ to gather more data at this angle of attack, then the angle was reduced. In other runs, the angle of attack was increased through stall along with other variations in rotation speed and time. The large rate of increase in $C_{l}$ in Figure 8 corresponds to the model rotation from $-2^{\circ}$ to $8^{\circ}$ angle of attack. During post processing, the $C_{l}$ versus $\alpha_{\mathrm{w}}$ data were extracted and plotted as shown in Figure 9. There are data for three configurations: the dry wing, the wing with uncontaminated fluid only and the wing with fluid plus ice-pellet contamination. These data illustrate typical deicing/anti-icing fluid effects on lift. The lift curves for the fluid only and fluid with ice pellets are shifted below and to the right of the "Dry Wing" lift curve. The effect of the fluid and contamination is to reduce the wing camber causing a shift in the zero-lift angle of attack. This effectively makes the profile more symmetric - and a symmetric airfoil has zero lift at zero angle of attack. The fact that the lift curves appear to be nearly parallel is not uncommon in fluids testing and has been reported in other studies (Ref. 17). It was determined that the percent lift loss on the model would be evaluated at $\alpha_{\mathrm{w}}=$ $8^{\circ}$. As shown in Figure 9, the fluid only configuration resulted in a 4.2 percent loss in lift from the dry wing at $\alpha_{\mathrm{w}}=8^{\circ}$. The addition of ice pellets to the fluid resulted in a further reduction in lift coefficient of 8.0 percent from the dry wing configuration. The objective of the analysis described in this report is to determine the significance of these percent lift loss values relative to a full airplane configuration. 


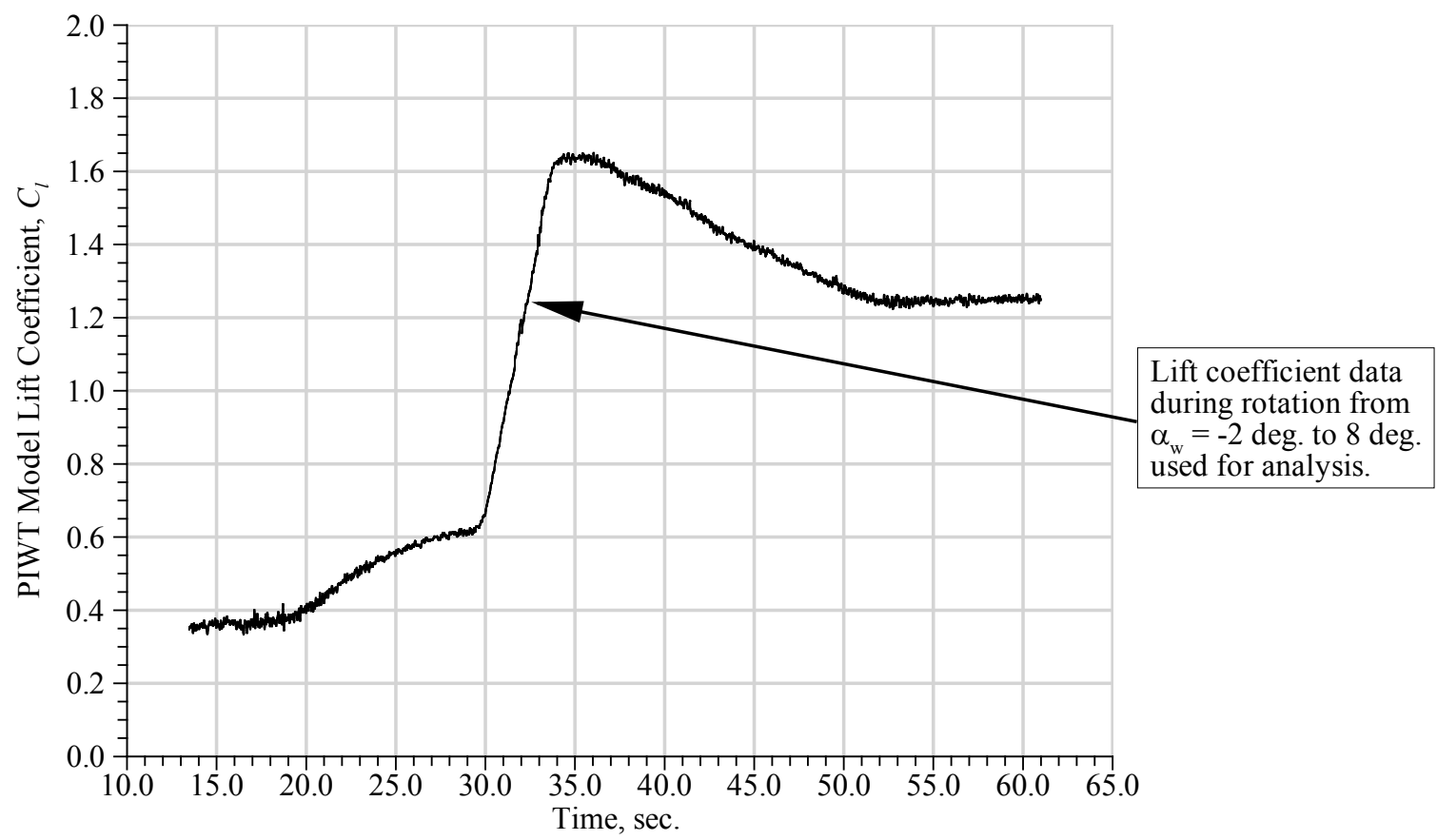

Figure 8.-Sample lift coefficient versus time profile for the simulated takeoff acceleration and wing rotation used in the PIWT tests.

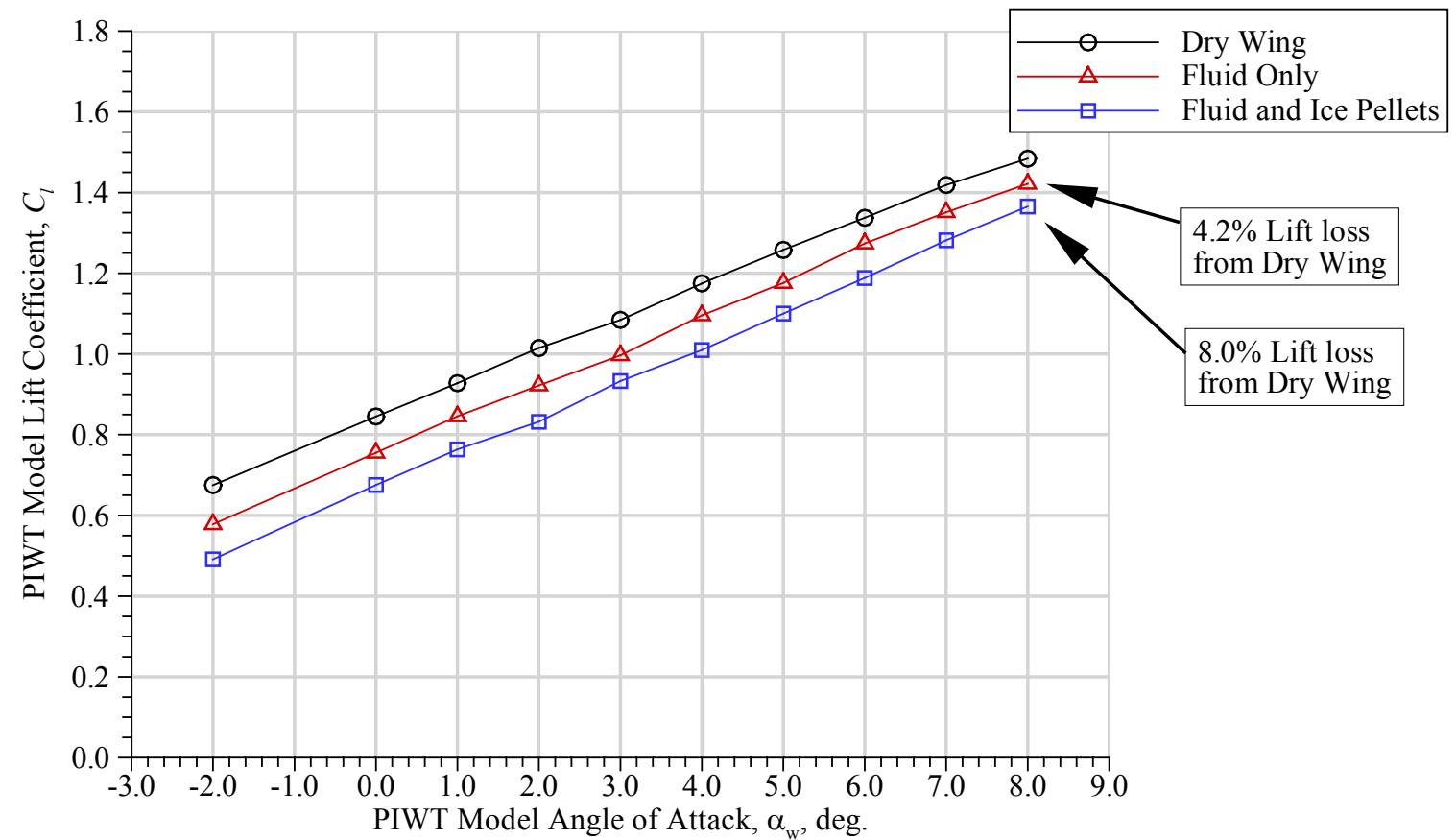

Figure 9.-Sample lift coefficient versus angle of attack data for three configurations-dry wing, uncontaminated fluid only and fluid with ice-pellet contamination. 


\subsection{Summary of 2010 and 2011 Uncontaminated Fluid Tests at NRC PIWT}

A series of simulated takeoff runs were performed in both 2010 and 2011 PIWT test campaigns for uncontaminated fluid applied to the model. Many other runs were performed for contaminated fluids, but are not discussed in this paper. For each simulated takeoff, the percent lift loss from the clean or dry wing was evaluated at $\alpha_{\mathrm{w}}=8^{\circ}$ as described in Section 3.2. These data are summarized as a function of the test temperature in Figure 10. There were five different fluids tested:

- ABC-S Plus manufactured by Kilfrost,

- EG106 manufactured by Dow Chemical,

- AD-49 manufactured by Dow Chemical,

- Launch manufactured by Clarient,

- Max-Flight manufactured by Octagon Process.

Of these, all are PG fluids except for EG106 which is an EG fluid. The data show the expected variation of PIWT model lift loss measured at $\alpha_{\mathrm{w}}=8^{\circ}$ with test temperature. In general, the percent lift loss increases with decreasing temperature. It was noted that EG fluids tend to flow off more readily than PG fluids, explaining the lower lift losses in Figure 10 for the EG106 fluid. It is important to note that all of these fluids are qualified fluids and as such, have passed the AAT. The variation in percent lift loss characteristics is due to the differences in the various fluids and the resulting flowoff behavior.

\subsection{Summary of AAT Results}

Samples of the fluids tested during the 2010 and 2011 PIWT test campaigns were sent to AMIL at University of Quebec at Chicoutimi. These fluids were tested according to the procedures for the highspeed ramp of the AAT described in Reference 13. For this procedure, the deicing or anti-icing fluid is applied uniformly to the horizontal floor of a rectangular duct having a width of $1.0 \mathrm{ft}(0.3 \mathrm{~m})$ and sufficient height and length to satisfy the dry-plate boundary-layer displacement thickness specifications.

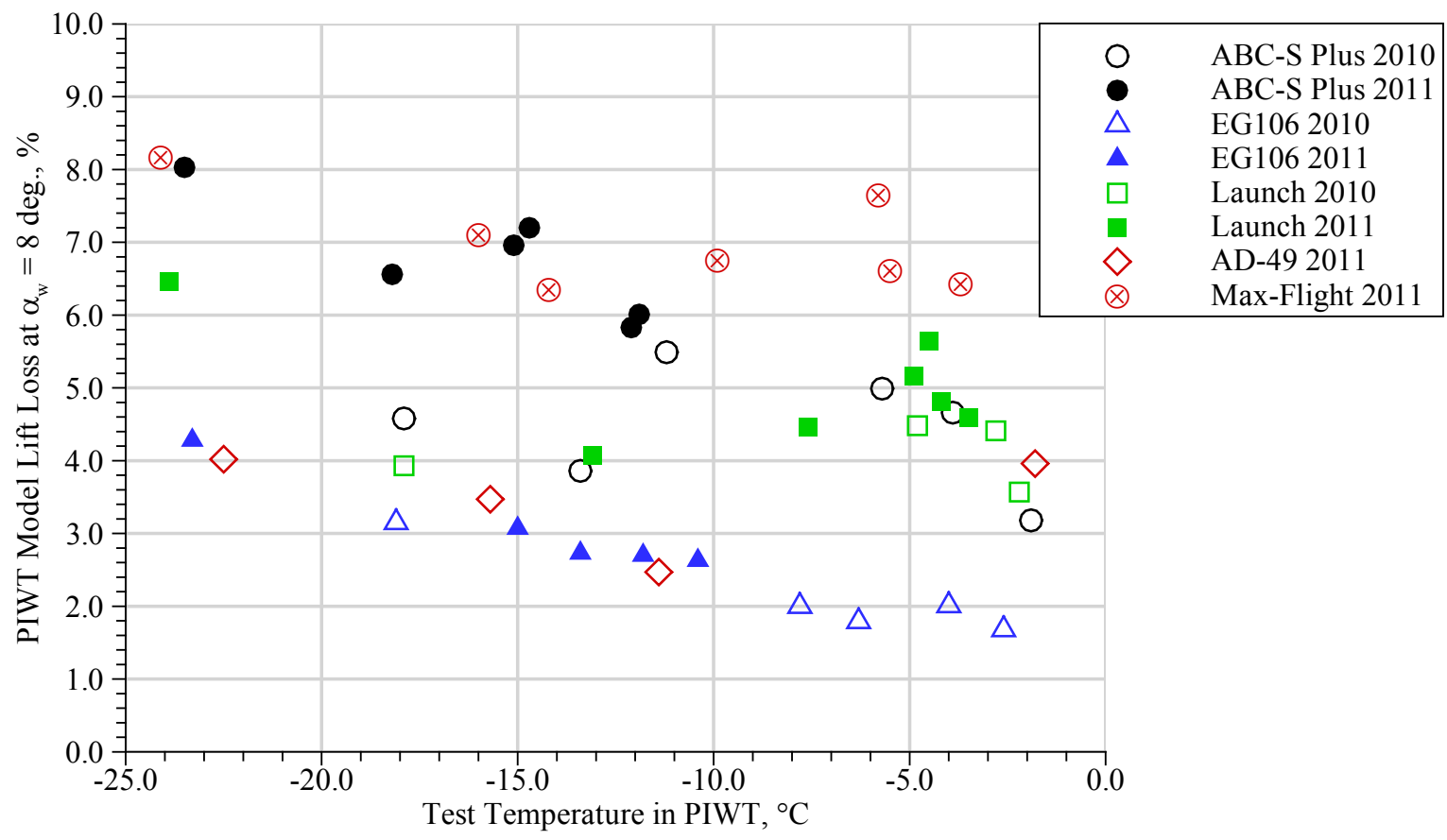

Figure 10.-Summary of uncontaminated fluid tests for PIWT test campaigns in 2010 and 2011. 


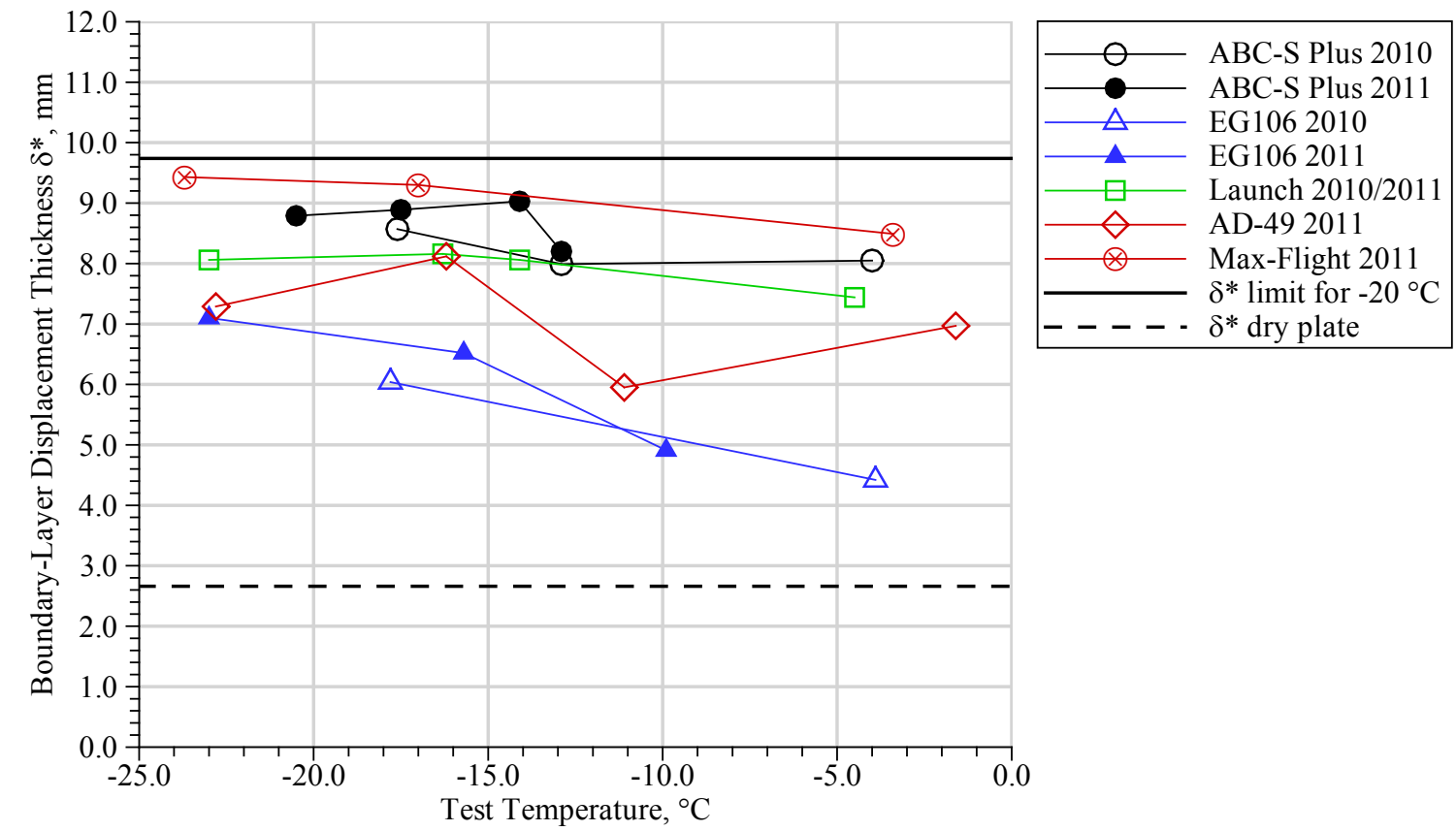

Figure 11._Summary of AMIL AAT results for fluid samples used in the 2010 and 2011 PIWT test campaigns.

Operational temperatures of the plate, air and fluid are also maintained at the desired set point. The windtunnel airflow over the plate is accelerated to approximately $127 \mathrm{kn}(65 \mathrm{~m} / \mathrm{s})$ in $25 \mathrm{sec}$ to simulate the takeoff profile. The displacement thickness is measured after $30 \mathrm{sec}$ at a location $5.0 \mathrm{ft}(1.5 \mathrm{~m})$ downstream from the leading edge. The displacement thickness is measured indirectly using static pressures to determine the local flow velocity, relating this to an area change and subsequently to the displacement thickness. This is different from the more direct method measuring the boundary-layer velocity profile used in the IRT experiments. However, the details of the measurement methods should not affect the results if performed properly.

For the present series of tests, the temperature range was selected to correspond to the range used in the PIWT test campaigns that was illustrated in Figure 10. The AAT test results for these fluid samples are shown in Figure 11. The upper limit of boundary-layer displacement thickness at $-20^{\circ} \mathrm{C}\left(\delta^{*}=9.74\right.$ $\mathrm{mm}$ ) was determined according to Reference 13. The plot shows that all of the fluids tested passed the AAT since all of the $\delta^{*}$ data lie below the upper limit of $9.74 \mathrm{~mm}$. The fluid samples tested were taken from the same batch used for the PIWT testing thereby eliminating any potential variations due to the manufacturing tolerances of the fluids. In the case of the Launch fluid, the same batch was used for both 2010 and 2011 test campaigns. The data presented in Figure 10 and Figure 11 were subsequently used to relate the PIWT model lift loss to the lift loss on a B737-200ADV airplane using the latter's relationship to the AAT.

\subsection{Establishment of a PIWT Model Lift Loss Criterion Via the AAT}

As described in Section 2.2 (cf. Figure 5), the results of the AAT relate directly to the maximum lift loss on the B737-200ADV airplane. It is therefore possible to use the results of the AAT to relate the lift loss measured on the PIWT model to the maximum lift loss on the B737-200ADV airplane. The first step in the process was to associate values for displacement thickness with the temperatures used in the PIWT testing by two-point interpolation or extrapolation employing the temperatures and displacement thicknesses from the AAT results (cf. Figure 11). This step accounts for the fact that the test temperature of the runs conducted in the PIWT (cf. Figure 10) were not identical to the test temperatures for the AAT results (Figure 11). For example, three AAT runs were performed with the EG106 2011 fluid batch at 
temperatures of $-9.9,-15.7$, and $-23.0^{\circ} \mathrm{C}$ (cf. Figure 11). These temperatures and measured values of $\delta^{*}$ are shown in Table II. The PIWT fluid tests using the same EG106 2011 batch were conducted at temperatures of $-10.4,-11.8,-13.4,-15.0$, and $-23.3{ }^{\circ} \mathrm{C}$. Two-point linear interpolation was performed to associate the $\delta^{*}$ values with the PIWT temperatures. Since the PIWT test temperature of $-23.3^{\circ} \mathrm{C}$ was slightly lower than the AAT temperature value of $-23.0^{\circ} \mathrm{C}$, a linear extrapolation was performed for this case using the nearest two temperatures $\left(-15.7\right.$ and $\left.-23.0^{\circ} \mathrm{C}\right)$. The PIWT temperatures and associated displacement thickness values are listed in Table III. The same process was followed for the other fluids. The associated $\delta^{*}$ values are plotted against the PIWT test temperatures in Figure 12.

TABLE II.-AAT RESULTS FOR EG106 2011 FLUID BATCH

\begin{tabular}{|c|c|}
\hline $\begin{array}{c}\text { AAT test temperature, } \\
{ }^{\circ} \mathrm{C}\end{array}$ & $\begin{array}{c}\text { Displacement thickness }\left(\delta^{*}\right), \\
\mathrm{mm}\end{array}$ \\
\hline-9.9 & 4.91 \\
-15.7 & 6.52 \\
-23.0 & 7.10 \\
\hline
\end{tabular}

TABLE III.-DISPLACEMENT THICKNESS VALUES CORRECTED FOR TEMPERATURE FOR PIWT TEST OF EG106 2011 FLUID BATCH.

\begin{tabular}{|c|c|}
\hline $\begin{array}{c}\text { PIWT test temperature, } \\
{ }^{\circ} \mathrm{C}\end{array}$ & $\begin{array}{c}\text { Interpolated displacement thickness }\left(\delta^{*}\right), \\
\mathrm{mm}\end{array}$ \\
\hline-10.4 & 5.05 \\
-11.8 & 5.44 \\
-13.4 & 5.88 \\
-15.0 & 6.33 \\
-23.3 & 7.12 \\
\hline
\end{tabular}

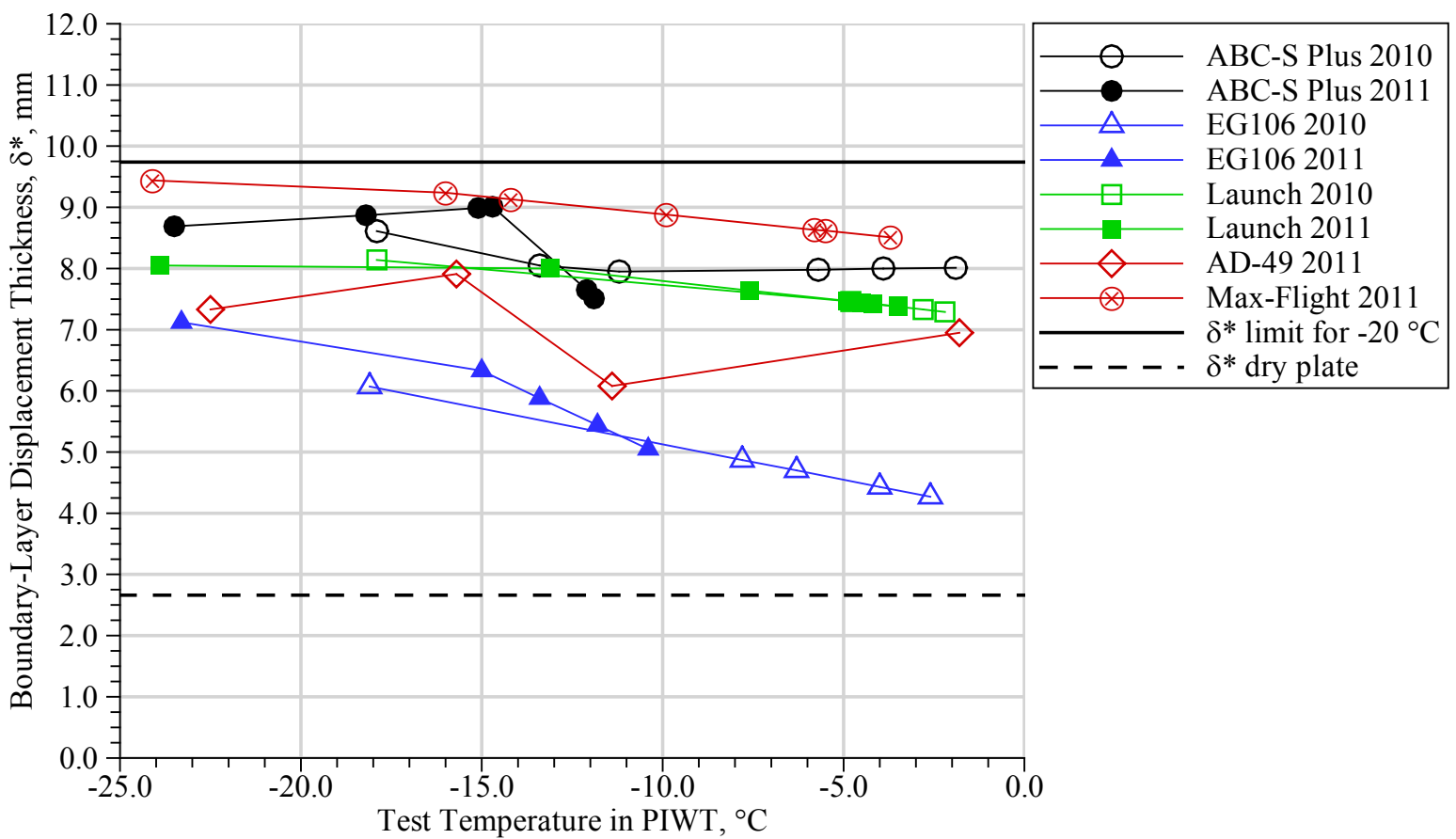

Figure 12.-Boundary-layer displacement thickness values associated with PIWT test temperatures. 
Hill and Zierten (Ref. 14) suggested that there is a linear relationship between the maximum lift loss on the B737-200ADV airplane and the AAT boundary-layer displacement thickness. This line is shown in Figure 13 and is given by:

$$
\Delta C_{L, \max }=5.24 \%\left[\frac{\delta_{f l u i d}^{*}-\delta_{d r y}^{*}}{\delta_{l\left(@-20^{\circ} \mathrm{C}\right.}^{*}-\delta_{d r y}^{*}}\right]
$$

This equation was used to calculate maximum lift loss on the B737-200ADV airplane using the data in Figure 12. As shown in Figure 12, all of the displacement thickness values are known:

- $\delta_{\text {fluid }}^{*}$ is given for each fluid batch as a function of test temperature;

- $\delta_{d r y}^{*}$ is given from the AAT data, $=2.66 \mathrm{~mm}$;

- $\delta_{l @-20^{\circ} \mathrm{C}}^{*}$ is given from the AAT data, $=9.74 \mathrm{~mm}$.

Using these data, all of the corresponding values for the B737-200ADV maximum lift loss were calculated for each fluid tested in the PIWT at each temperature and the resulting data are plotted in Figure 13. As noted previously in this section, all of these fluids passed the AAT so all maximum lift loss values lie below the 5.24 percent limit as indicated in Figure 13. The form of the data in Figure 13 is similar to that in Figure 12 because of the linear relationship given in Equation (1).

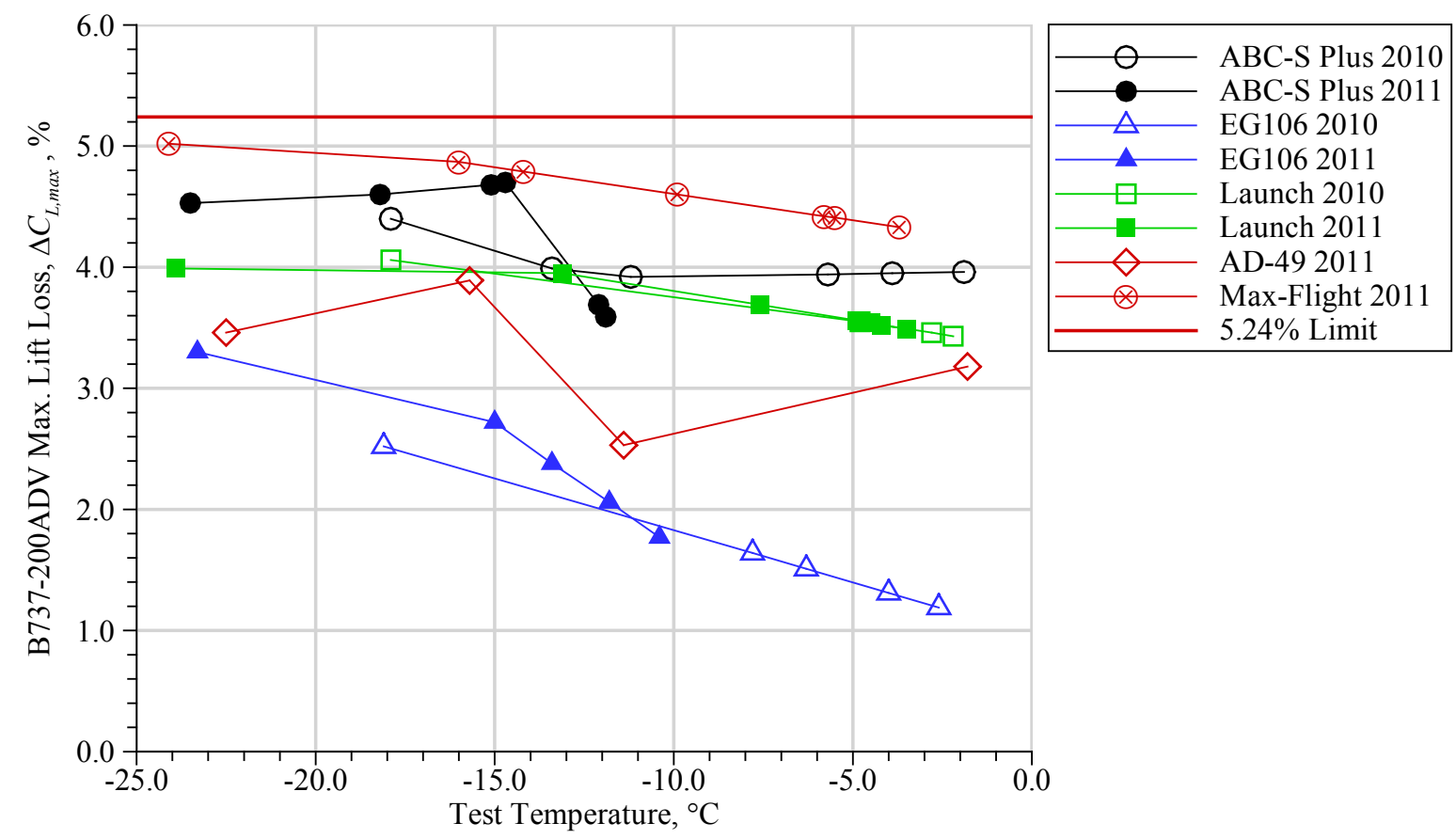

Figure 13.-B737-200ADV maximum lift loss for the PIWT test temperatures calculated using AAT data shown in Figure 12 using Equation (1). 
This analysis has generated the data required to relate the lift losses measured on the thin, highperformance wing model in the PIWT to the B737-200ADV maximum lift loss implied by the AAT. The PIWT model lift losses measured at $\alpha_{\mathrm{w}}=8^{\circ}$ were plotted against test temperature in Figure 10 for tests with the fluids shown in the plot legend. The B737-200ADV airplane maximum lift losses were obtained from the AAT for the same fluids at the same test temperatures as shown in Figure 13. Therefore, the common independent variable of test temperature can be eliminated between Figure 10 and Figure 13 to yield a correlation between the B737-200ADV maximum lift loss and the PIWT model lift loss measured at $\alpha_{\mathrm{w}}=8^{\circ}$. This correlation is shown in Figure 14 and reflects the appropriate trend of increasing B737200ADV maximum lift loss for increasing PIWT model lift loss measured at $\alpha_{\mathrm{w}}=8^{\circ}$. This plot is analogous to that shown in Figure 3 relating B737-200ADV 3-D model maximum lift losses to the lift losses on the corresponding 2-D model at $\alpha_{\mathrm{w}}=8^{\circ}$. In both plots (Figure 3 and Figure 14) there is considerable scatter in the data that is indicative of the differences in the fluid flowoff characteristics and resulting performance penalties. A linear regression curve fit was performed on the data in Figure 14. The regression was forced through the origin since this corresponded to the dry wing for each configuration. The percent lift loss on the dry wing was 0 , by definition. The regression line had a slope $=0.72$ whereas the slope in Figure 3 was 1.04. The most likely explanation for the difference in these slopes is that the thin, high-performance wing section used in the PIWT test had significantly different aerodynamic characteristics than the "critical" section of the B737-200ADV wing. There are other differences as well, such as the air speed at model rotation, between the two tests. Therefore some difference in these slopes is expected. The data indicate that a $\Delta C_{L, \max }$ of 5.24 percent on B737-200ADV airplane is equivalent to a lift loss of 7.3 percent on the PIWT model measured at $\alpha_{\mathrm{w}}=8^{\circ}$. It is therefore suggested that an appropriate lift loss threshold for the tests conducted on the PIWT model is 7.3 percent measured at $\alpha_{\mathrm{w}}=8^{\circ}$ since this is equivalent to a $\Delta C_{L, \max }$ of 5.24 percent on $\mathrm{B} 737-200 \mathrm{ADV}$ airplane.

It is clear from inspection of Figure 14 that some means of accounting for the scatter in the data is needed. Furthermore, establishing an absolute lift loss threshold of 7.3 percent neglects the three data points in Figure 14 that have a PIWT model lift loss measured at $\alpha_{\mathrm{w}}=8^{\circ}$ greater than 7.3 percent. These cases should not fail the criterion because they are qualified fluids having passed the AAT. Chapra and Canale (Ref. 21) define the Standard Error of the Estimate (SEE) as a means of quantifying the data spread about the linear regression line and is given by:

$$
S E E=\sqrt{\frac{\sum_{i=1}^{N}\left(y_{i}-0.72 x_{i}\right)^{2}}{N-2}}
$$

The $S E E$ is a measure of the "goodness of fit" based upon the sum of the residuals about the regression line. For the data in Figure 14, SEE $=0.67$ and has "units" of the $y$-variable-B737-200ADV airplane percent maximum lift loss. Plotted in Figure 14 are lines representing $\pm 2 * S E E$ deviations from the linear regression line and all but two of the data points fall between these lines. In addition, the upper bound $(+2 * S E E)$ captures the three PIWT data points with lift loss greater than 7.3 percent but have still passed the AAT. Therefore, it seems prudent to establish a lift loss threshold up to 9.2 percent for the PIWT model lift loss at $\alpha_{\mathrm{w}}=8^{\circ}$. Since the evaluation of the fluid performance with ice-pellet contamination is also based upon visual observations of flowoff and failure, specifying a range of lift loss can help identify cases that may need more careful evaluation of the visual observations. For example, if the PIWT measured lift loss at $\alpha_{\mathrm{w}}=8^{\circ}$ is greater than 7.3 percent, but less than 9.2 percent, then the fluid performance may still be acceptable based upon visual observations. However, if the PIWT measured lift loss at $\alpha_{\mathrm{w}}=8^{\circ}$ is greater than 9.2 percent, this should be grounds for rejection since the upper limit has been surpassed. Additional data may result in future adjustments to the proposed criterion. 


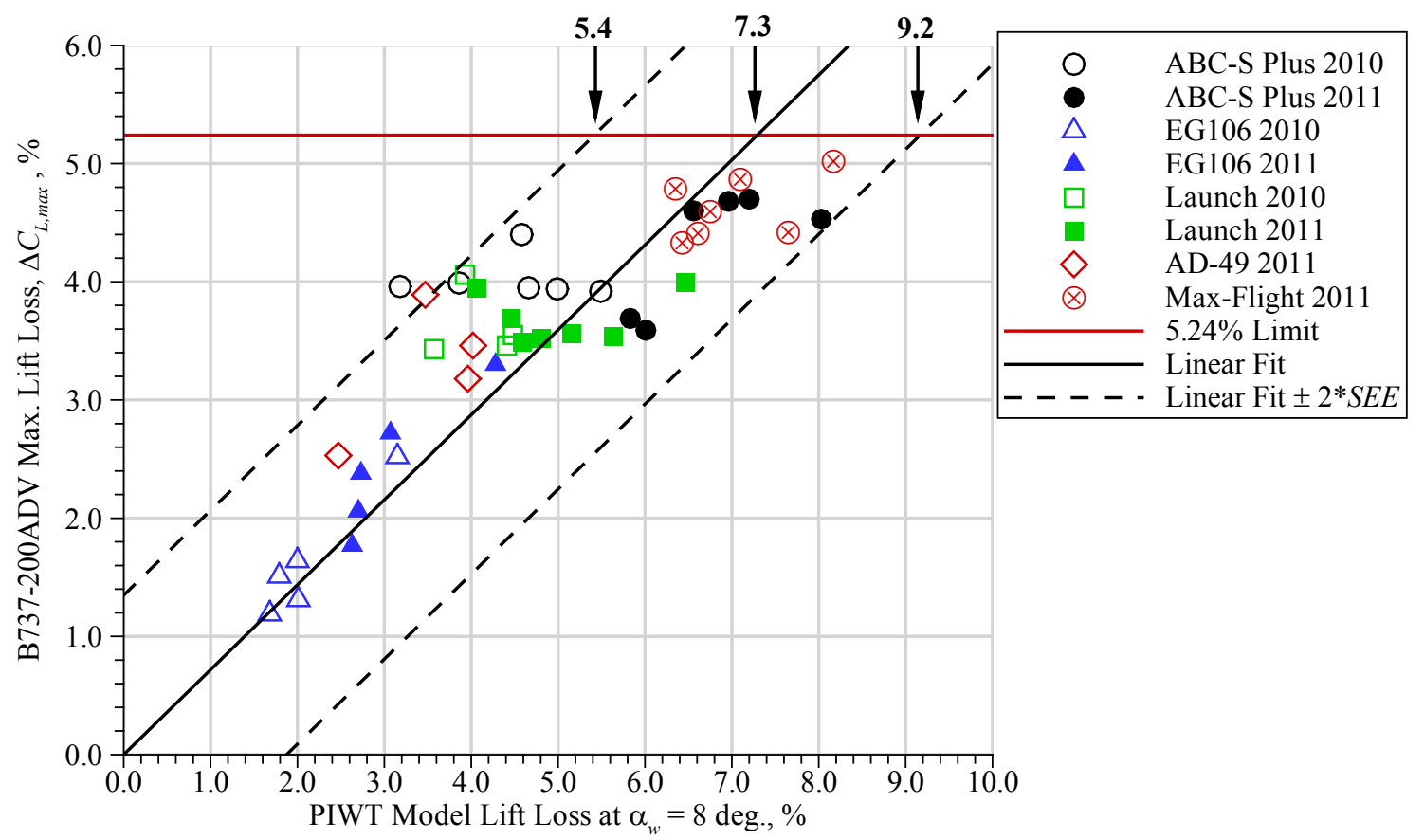

Figure 14.-Correlation between percent lift loss on the PIWT model at $\alpha_{w}=8^{\circ}$ and percent maximum lift loss on the 3-D B737-200ADV airplane for the uncontaminated fluid tests.

\subsection{Comments on PIWT Model Tests and Results}

As stated in Section 1.0, the dissemination of the PIWT test results with the thin, high-performance wing model and the subsequent changes to the ice-pellet allowance time tables have led to concerns regarding the fidelity and applicability of the measured lift degradation. Given the potential operational safety implications associated with the measured performance degradations, it is even more important that these concerns be addressed appropriately. The essence of these concerns is understanding how the performance degradations measured on the model in the NRC PIWT testing relate to an actual threedimensional, full-scale airplane configuration. The review of the research basis of the AAT and the subsequent analysis in Section 3.0 was conducted to address the following specific concerns:

- A 2-D model with endplates was used instead of a 3-D geometry more representative of an airplane wing.

- Lift degradations were measured at $\alpha_{\mathrm{w}}=8^{\circ}$ on the 2-D model instead of at stall.

- Airplanes undergoing take-off accelerations and rotation experience ground effects that were not simulated in the PIWT testing.

- The chord Reynolds number was small relative to most airplane wing sections.

- The 6-ft $(1.8 \mathrm{~m})$ chord length model is small relative to most airplane wing sections.

- The large model size and proximity of the wind-tunnel walls resulted in uncorrectable effects on the aerodynamic data and performance.

- The rotation speed used in the PIWT tests was low relative to typical airplane rotation speeds.

Interestingly, all but the last two of these concerns were also raised in the development of the AAT and were addressed by Hill and Zierten (Ref. 14) and Runyan et al. (Ref. 17) The experimental methods used in the aerodynamic evaluations of fluids in the PIWT closely follow the methods used in the 2-D model testing during the development of the AAT. Hill and Zierten (Ref. 14) and Runyan et al. (Ref. 17) showed the usefulness and applicability of 2-D model testing. In both research efforts, lift losses on the 
2-D model were evaluated at an angle of attack well below stall. The PIWT model lift data were analyzed at $\alpha_{w}=8^{\circ}$. At this low angle of attack, the flow on the model was 2-D based upon observations of the fluid flow. So analyzing the lift data at $\alpha_{\mathrm{w}}=8^{\circ}$ minimized any 3-D effects and wall effects that may increase in magnitude with increasing angle of attack above $8^{\circ}$. In both research efforts, the wind-tunnel testing was performed without a ground plane (for the 2-D model). In the AAT research, the 2-D model was very small $(1.5 \mathrm{ft}(0.305 \mathrm{~m})$ chord $)$ relative to the full-scale wing. The small size of the wing meant that the chord Reynolds number $\left(\approx 1.5 \times 10^{6}\right.$ at rotation $)$ was also very low. The PIWT model was larger ( $6 \mathrm{ft}$ chord) and therefore higher Reynolds numbers $\left(\approx 7.0 \times 10^{6}\right.$ at rotation) were obtained in the wind tunnel. The effect of Reynolds number on aerodynamic performance of airfoils is usually negligible above $6.0 \times 10^{6}$. This "critical" Reynolds number is much lower with any type of leading-edge contamination on the wing (Refs. 22 to 25 The AAT research indicated model scale and Reynolds number effects were negligible - down to the small values used in that work. Therefore, the present PIWT model scale and Reynolds number should not introduce any additional concerns.

There is little reason for concern about the model size and wind-tunnel walls resulting in large and uncorrectable solid and wake blockage effects that would adversely affect the aerodynamic data. The model chord to test-section height ratio was 0.37 , which is less than 0.40 - the value recommended as the reasonable upper limit for 2-D model testing for accurate values of maximum lift (Ref. 26) Since the model was not oversized relative to the tunnel height, the effects of the walls should be minimal. These effects should be similar for all of the test runs and therefore should not affect the relative comparisons. Furthermore, wind-tunnel wall effects become more significant at higher angles of attack and lift coefficient approaching maximum lift. So measuring the PIWT model lift loss at $\alpha_{\mathrm{w}}=8^{\circ}$, well below maximum lift, also mitigated these effects.

There are some differences between the B737-200ADV research effort used to develop the AAT and the present PIWT model research effort. However, these differences in the experimental methods, such as model size, geometry, installation and Reynolds number, should be accounted for in the correlation presented in Figure 14. This discussion has shown that the concerns listed at the beginning of this section do not compromise the applicability of the AAT scaling methodology for PIWT model lift loss. The PIWT testing was carried out in a manner consistent with the methods used in the AAT research and with standard wind-tunnel testing methods. The possible exception is the lower rotation speed, addressed in the following paragraph.

In the PIWT model tests, the speed at model rotation was limited to $100 \mathrm{kn}(51.4 \mathrm{~m} / \mathrm{s})$ by the capabilities of the wind-tunnel facility. In the "high-speed ramp" procedures currently used for the AAT, the simulated rotation speed is $127 \mathrm{kn}(65 \mathrm{~m} / \mathrm{s})$ (Ref. 13). This value is very similar to the rotation speed of 120 to $125 \mathrm{KEAS}$ ( 62 to $64 \mathrm{~m} / \mathrm{s}$ ) that was used in the flight test trials and wind-tunnel testing on the B737-200ADV for the development of the AAT (Refs. 14 and 17). A similar rotation speed range was used in the ice-pellet flight test research (Ref. 4). The effect of rotation speed on lift coefficient was shown in Runyan et al. (Ref. 17) and is significant. Higher rotation speeds resulted in higher lift coefficient, which in turn means lower percent lift loss due to the fluid. The relationship between rotation speed and lift coefficient appears to be linear over the range shown in Runyan et al. (Ref. 17). If this relationship is linear, then the primary effect of low rotation speed on the PIWT aerodynamic data may already be accounted for in the "scaling" analysis described in the previous section. The low rotation speed in the PIWT tests could partly explain the lower slope of the regression line plotted in Figure 14 compared to the line plotted in Figure 3. However, more data may be required to completely ameliorate this concern.

There are additional concerns not included in the list at the beginning of this section. For example, the AAT was developed prior to the current widespread use of Type IV anti-icing fluids, such as those used in the PIWT tests. If any adjustment to the AAT acceptance criteria were required to account for Type IV fluids, then this may affect the proposed "scaling" methodology applied to the PIWT data. Beisswenger et al. (Ref. 27) performed a series of flat-plate fluid tests comparing the flow-off characteristics that showed similar behavior between Type II and Type IV fluids. The authors are unaware of any corresponding 
aerodynamic evaluation that would help confirm similarities between Type II and Type IV fluid effects and further research may be required.

Another concern that may be introduced by the proposed "scaling" methodology relative to the development of the ice-pellet allowance times is that the visual observations of the fluid flowoff and associated evaluation are still based upon the aerodynamics of the thin, high-performance wing while the lift loss criterion has been scaled to the effect on the full-scale B737-200ADV airplane. This represents some type of mixed evaluation that may or may not affect the development of the allowance times. For example, a key difference in the model geometries is that the B737-200ADV model had a leading-edge slat while the PIWT model had a hard leading edge. Hill and Zierten (Ref. 14) noted this "configuration dependency" in their work. So it is unclear that similar ice-pellet contamination testing on the B737200ADV model would lead to similar allowance times. Finally, it may be worthwhile revisiting the fluids research on commuter aircraft that was conducted shortly after the B737-200ADV IRT test campaigns, described in References 28 and 29. This may help to further mitigate concerns about the present PIWT model tests and results due to a higher degree of similarity in the model configurations and rotation speeds.

\subsection{Summary and Conclusions}

The FAA has worked with Transport Canada and others to develop allowance times for aircraft operations in ice-pellet precipitation. Wind-tunnel testing has been carried out to better understand the flowoff characteristics and resulting aerodynamic effects of anti-icing fluids contaminated with ice pellets. This testing has taken place at the National Research Council of Canada's Propulsion and Icing Wind Tunnel (PIWT) using a nominally 2-D wing with a thin, high-performance section and singleelement slotted flap. The model, with either uncontaminated anti-icing fluid or fluid contaminated with simulated ice-pellet precipitation, was subjected to a simulated takeoff through rotation. Evaluation of the fluid performance was determined from visual observations of the flowoff and evaluation of the model lift degradation. The percent lift loss on the PIWT model was calculated at $8^{\circ}$ angle of attack and used as one of the evaluation criteria in determining the allowance times in recent testing. The dissemination of the wind-tunnel testing results and subsequent changes to the ice-pellet allowance time tables led to concerns regarding the fidelity and applicability of the measured lift degradation in fluid testing at the NRC PIWT. Given potential operational safety implications associated with the measured performance degradations, it was important that these concerns be addressed. This paper addresses these concerns and shows that the lift loss in the PIWT can be related to the loss in maximum lift of a Boeing 737-200ADV airplane through the Aerodynamic Acceptance Test (AAT) performed for fluids qualification.

The AAT was developed as a simple and relatively low-cost method to evaluate deicing and antiicing fluids. Fluid samples are tested on a small, horizontal, flat plate at operational air temperatures and simulated takeoff speeds. The measured boundary-layer displacement thickness due to the fluid was shown to be directly proportional to the loss in maximum lift on a B737-200ADV airplane. Fluids with AAT displacement thickness values corresponding to less than 5.24 percent maximum lift loss are considered acceptable. Fluid samples used in the PIWT model testing were subjected to the AAT to develop the relationship for those samples between displacement thickness and B737-200ADV maximum lift loss. Samples of these same fluids were tested at the same temperatures on the thin, high-performance wing model in the PIWT and lift losses were determined at $8^{\circ}$ angle of attack. This permitted the development of a correlation between the PIWT model lift loss at $8^{\circ}$ angle of attack and lift loss at maximum lift on the B737-200ADV airplane.

The analysis presented in this report shows that a maximum lift loss of 5.24 percent on the B737200ADV airplane corresponds to a lift loss of 7.3 percent for the thin, high-performance wing at $\alpha_{w}=8^{\circ}$ in the PIWT. There is significant scatter in the data used to develop the correlation related to varying effects of the various anti-icing fluids that were tested and other factors. A statistical analysis indicated that the upper limit of lift loss on the PIWT model was 9.2 percent. Therefore, a range of lift loss from 7.3 
to 9.2 percent on the thin, high-performance wing at $\alpha_{\mathrm{w}}=8^{\circ}$ in the PIWT suggests that extra scrutiny of the visual observations is required in evaluating fluid performance with contamination and establishing the allowance times. For example, if the PIWT model lift loss at $\alpha_{w}=8^{\circ}$ is greater than 7.3 percent, but less than 9.2 percent, then the fluid performance may still be acceptable based upon visual observations. However, if the PIWT model measured lift loss at $\alpha_{\mathrm{w}}=8^{\circ}$ is greater than 9.2 percent, this should be grounds for rejection since the upper limit has been surpassed.

This review of the research basis of the AAT and the subsequent PIWT model analysis has shown that any differences such as model size, geometry, installation and Reynolds number, are accounted for in the correlation presented in Figure 14. Furthermore, this report shows that concerns about the thin, highperformance wing model testing in the PIWT do not compromise the applicability of the AAT scaling methodology for PIWT model lift loss determined at $8^{\circ}$ angle of attack. The PIWT testing was carried out in a manner that was consistent with the methods used in the AAT research and with standard windtunnel testing methods. There are, however, some remaining concerns such as rotation speed, applicability to Type IV fluids and model configuration that could be addressed in future research.

\section{References}

1. FAA Notice N 8000.308, "Reevaluation of Deicing/Anti-icing Programs," Oct. 5, 2005.

2. FAA Notice N 8000.309, "Dispatching During Precipitation Conditions of Ice Pellets, Snow Pellets, or Other Icing Events for which no Hold Over Times Exist," Oct. 5, 2005.

3. FAA Notice N 8000.313, "Parts 121 and 135 Operations Specification for Deicing/Anti-Icing, Operations in Ice Pellets without Deice/Anti-Ice Fluids," Oct. 31, 2005.

4. Broeren, A.P., and Riley, J.T., "Review of the Aerodynamic Acceptance Test and Application to Anti-Icing Fluids Testing in the NRC Propulsion and Icing Wind Tunnel," NASA TM-2012-216014 and FAA Report, To be Published in 2012.

5. FAA Notice N 8000.329, “FAA-Approved Deicing Program Updates, Winter 2006-2007," Oct. 27 , 2006.

6. Cortinas, J.V., Jr., Bernstein, B.C., Robbins, C.C., and Strapp, J.W ., "An Analysis of Freezing Rain, Freezing Drizzle, and Ice Pellets across the United States and Canada: 1976-90," Weather and Forecasting, Vol. 19, April 2004, pp. 377-390.

7. Huang, X.Z., Byers, B.B., D'Avirro, J., and Ruggi, M., "Icing Wind-Tunnel Tests on a Contaminated Full-Scale Wing-Model at Takeoff Conditions," AIAA Paper 2008-6417, Aug. 2008.

8. FAA Notice N 8900.19, "Guidance and Procedures for Dispatching During Ice Pellet and in Heavy Snow Conditions and Evaluating Pilot Assessment of Precipitation Intensity," Sept. 20, 2007.

9. FAA Notice N 8900.22, "FAA-Approved Deicing Program Updates, Winter 2007-2008," Oct. 12, 2007.

10. FAA Notice N 8900.98, “FAA-Approved Deicing Program Updates, Winter 2009-2010,” Oct. 30, 2008.

11. Clark, C. and MacMaster, M., "Icing Wind Tunnel Tests of a Contaminated Supercritical Anti-Iced Wing Section during Simulated Take-off," AIAA Paper 2011-1101, Jan. 2011.

12. Official FAA Holdover Time Tables Winter 2011-2012, http://www.faa.gov/other_visit/aviation industry/airline_operators/airline safety/deicing Accessed Sept. 7, 2011.

13. SAE Aerospace Standard, "Standard Test Method for Aerodynamic Acceptance of SAE AMS 1424 and SAE AMS 1428 Aircraft Deicing/Anti-icing Fluids," AS5900 Rev. A, May 2003.

14. Hill, E.G., and Zierten, T.A., "Aerodynamic Effects of Aircraft Ground Deicing/Anti-Icing Fluids," Journal of Aircraft, Vol. 30, No. 1, Jan.-Feb., 1993.

15. Hill, E.G., "Airplane Performance and Other Considerations Related to Airplane Icing While on the Ground," Airplane Deicing Seminar, Aircraft Technology Division, Danish Engineering Society, Feb. 1993. 
16. Hill, E.G., and Zierten, T.A., "Aerodynamic Acceptance Test for Aircraft Ground Deicing/Anti-icing Fluids," Boeing Document No. D6-55573, Mar. 1992.

17. Runyan, L.J., Zierten, T.A., Hill, E.G., and Addy, H.E., Jr., "Lewis Icing Research Tunnel Test of the Aerodynamic Effects of Aircraft Ground Deicing/Anti-Icing Fluids," NASA TP-3238, Aug. 1992.

18. Clark, C. and MacMaster, M., "Icing Wind Tunnel Tests of a Contaminated Supercritical Anti-iced Wing Section During Simulated Take-off (Phase 2)," NRC-CNRC Report No. LTR-AL-2011-0019, Feb. 22, 2011.

19. Clark, C. and MacMaster, M., "Icing Wind Tunnel Tests of a Contaminated Supercritical Anti-iced Wing Section During Simulated Take-off -Phase 2," AIAA 4th Atmospheric and Space Environments Conference, New Orleans, LA, June 24-28, 2012 (submitted for publication).

20. Rae, W.H., Jr., and Pope, A. Low-Speed Wind Tunnel Testing, 2nd Ed. John Wiley \& Sons, New York, 1984, pp. 344-362.

21. Chapra, S.C., and Canale, R.P., Numerical Methods for Engineers, 2nd Ed., McGraw-Hill, New York, 1988, p. 336.

22. Abbott, I.H., and von Doenhoff, A.E., Theory of Wing Sections, Dover, New York, 1959, pp. 124187.

23. Lee, S., Kim, H.S., and Bragg, M.B., "Investigation of Factors that Influence Iced-Airfoil Aerodynamics," AIAA Paper 2000-0099, Jan. 2000.

24. Lynch, F.T., and Khodadoust, A., "Effects of Ice Accretions on Aircraft Aerodynamics," Progress in Aerospace Sciences, Vol. 37, No. 8, Nov. 2001.

25. Bragg, M.B., Broeren, A.P., and Blumenthal, L.A., "Iced-Airfoil Aerodynamics," Progress in Aerospace Sciences, Vol. 41, No. 5, Jul. 2005, pp. 323-362.

26. Allen, H.J., and Vincenti, W.G., "Wall Interference in a Two-Dimensional-Flow Wind Tunnel, with Consideration of the Effects of Compressibility," NACA Report 782, 1944.

27. Beisswenger, A., Fortin G., Laforte, J.-L., "Investigation of Type II and Type IV Aircraft Ground Anti-Icing Fluid Aerodynamic Certification Standards," FAA Report DOT/FAA/AR-03/55, July 2003.

28. Ellis, N.D., Nettleton, T.R., and Eggleston, B., Effects of Anti-icing/De-icing Fluids on the Take-off Performance of Commuter Aircraft," Report DHC-TDC-90-1, Transport Canada DeHavilland, Mar. 1991.

29. Louchez, P.R., Laforte, J.L. and Bouchard, G., "Boundary Layer Evaluation of Anti-icing Fluids for Commuter Aircraft," Transport Canada Report TP11811E, Dec. 1994. 


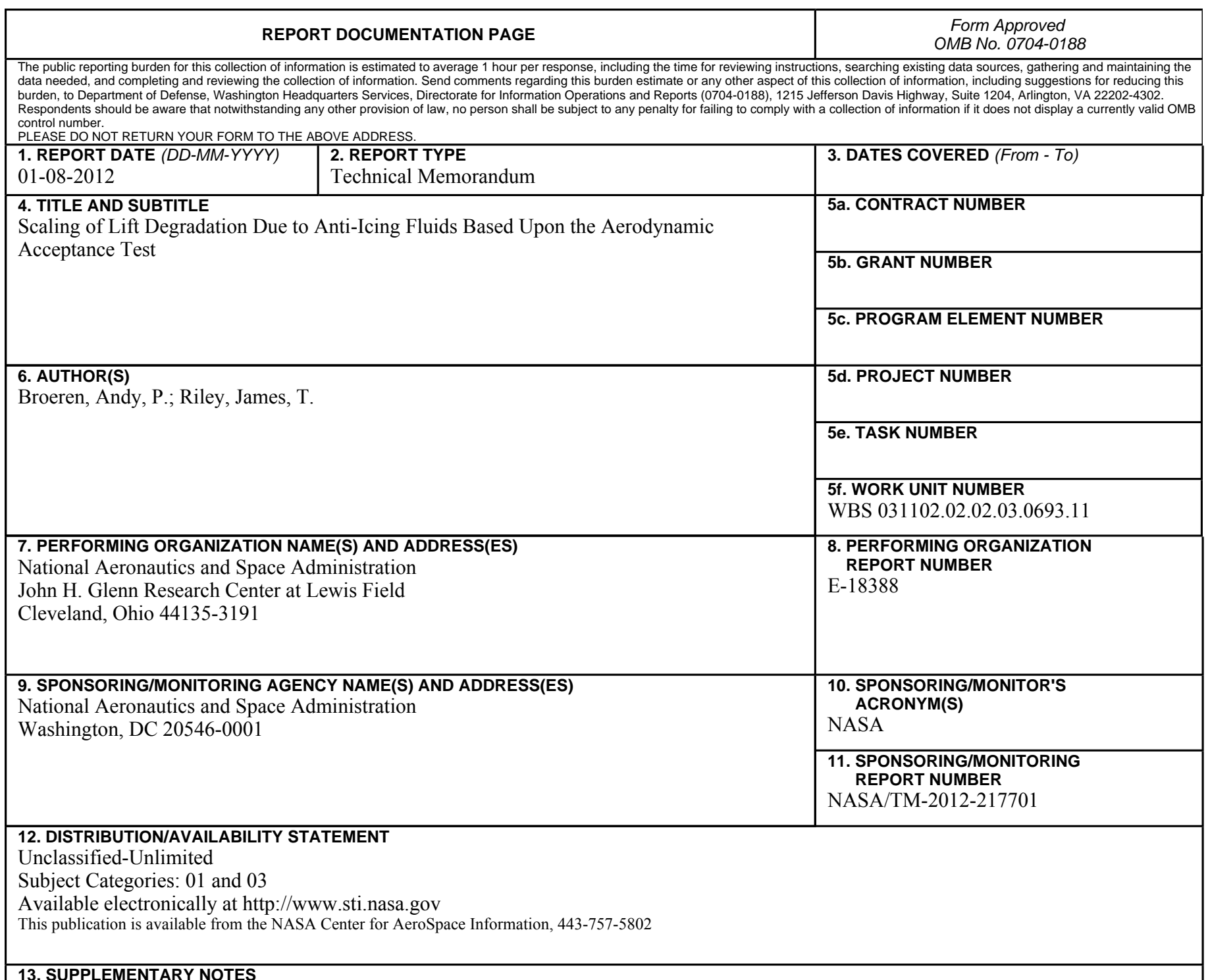

\section{SUPPLEMENTARY NOTES}

\section{ABSTRACT}

In recent years, the FAA has worked with Transport Canada, National Research Council Canada (NRC) and APS Aviation, Inc. to develop allowance times for aircraft operations in ice-pellet precipitation. These allowance times are critical to ensure safety and efficient operation of commercial and cargo flights. Wind-tunnel testing with uncontaminated anti-icing fluids and fluids contaminated with simulated ice pellets had been carried out at the NRC Propulsion and Icing Wind Tunnel (PIWT) to better understand the flowoff characteristics and resulting aerodynamic effects. The percent lift loss on the thin, high-performance wing model tested in the PIWT was determined at $8^{\circ}$ angle of attack and used as one of the evaluation criteria in determining the allowance times. Because it was unclear as to how performance degradations measured on this model were relevant to an actual airplane configuration, some means of interpreting the wing model lift loss was deemed necessary. This paper describes how the lift loss was related to the loss in maximum lift of a Boeing 737-200ADV airplane through the Aerodynamic Acceptance Test (AAT) performed for fluids qualification. A loss in maximum lift coefficient of 5.24 percent on the B737-200ADV airplane (which was adopted as the threshold in the AAT) corresponds to a lift loss of 7.3 percent on the PIWT model at $8^{\circ}$ angle of attack. There is significant scatter in the data used to develop the correlation related to varying effects of the anti-icing fluids that were tested and other factors. A statistical analysis indicated the upper limit of lift loss on the PIWT model was 9.2 percent. Therefore, for cases resulting in PIWT model lift loss from 7.3 to 9.2 percent, extra scrutiny of the visual observations is required in evaluating fluid performance with contamination.

\section{SUBJECT TERMS}

Aircraft icing; Aerodynamics; Wind tunnel

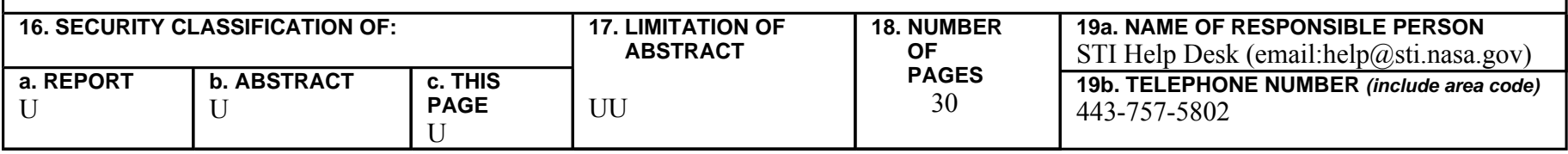



